\title{
Web-NDefA: Açık kaynak kodlu GNSS tabanlı deformasyon analizi platformu
}

\author{
Mehmet Bak ${ }^{1 *}$ (D) Rahmi Nurhan Çelik ${ }^{1}$ iD \\ ${ }^{1}$ Istanbul Teknik Üniversitesi, Ayazağa Kampüsü, Inşaat Fakültesi, Geomatik Mühendisliği Bölümü, Sarıyer, İstanbul, Türkiye
}

\begin{abstract}
Öz: Jeodezinin temel araştırma alanlarından biri olan deformasyon analizi insan güvenliği için önemli bir rol oynar. Yer kabuğu hareketleri neticesinde ortaya çıkan yatay ve düşey konum değiştirmelerinin ve deformasyonların belirlenmesi ve buna göre muhtemel yıkımlara karşı önleyici tedbirlerin alınması son derece önemlidir. Kabuk deformasyon çalışmalarının belirlenmesi, bilim insanlarının karşılaştıkları en önemli problemlerden biri olarak düşünülür. Bilim insanları bu problemi çözmek için vakitlerinin büyük bir bölümünü ayırmak zorunda kalmaktadırlar. Bununla beraber yer kabuğu hareketlerine duyulan ilginin artması ve teknolojideki hızlı gelişmeler deformasyon analizinde yeni yazılımların kullanılmasını zorunlu hale getirmiştir. Burada deformasyonların izlenmesine ve analiz edilmesine ilgi duyan uzman mühendislerin değerlendirme yazılımlarına daha rahat ulaşabilmeleri ve analizlerini daha kolay yapabilmeleri için statik deformasyon analizine yönelik açık kaynak kodlu yazılımlar kullanılarak bir web uygulaması geliştirilmiştir. Bu sayede bu uygulamadan; 3 boyutlu deformasyon analizi kapsamında jeodezik verileri organize etmek, gerektiğinde hızl, doğru ve eksiksiz olarak bu verilerden elde edilecek sonuçlara erişmek isteyen her kişi veya kurum faydalanmış olacaktır. Bu bağlamda web platformunun oluşturulması için öncelikle Hiper Metin İşaretleme (Hyper Text Markup Language, HTML) ve Basamaklı Biçim Şablonları (Cascading Style Sheets, CSS) uygulamaları yapılmıştır. Ayrıca istemci taraflı programlama dillerinden olan Javascript ile deformasyon analizi uygulamaları geliştirilmiştir. Bu programı kullanmak için önce bir GNSS veri işleme programı olan Leica Geo Office yazılımından bir GPS kampanyasindaki baz vektörlerinin çözümlerini içeren Bilgi Değişimi için Amerikan Standart Kodu (American Standard Code for Information Interchange, ASCII) dosyası elde edilir ve uygulamaya aktarılır. Bu baz çözümleri ile web uygulamasında karşılaştırılacak periyotlar seçilir ve deformasyon analizi gerçekleştirilir. Sonuç olarak bu çalışmada, hazırlanan web uygulaması bir veri grubu ile değerlendirilecek ve platformun teknik altyapısı hakkında bilgi verilecektir. Böylece deformasyon analizinde kullanılan platformlara yeni bir boyut kazandırılacak ve kullanıcıların ihtiyaç duyabilecekleri statik deformasyon analizi sonuçları görsel olarak sunulacaktır.
\end{abstract}

Anahtar Sözcükler: GNSS, Deformasyon analizi, Açık kaynak kodlu yazılımlar

\section{Web-NDefA: Open source GNSS based deformation analysis platform}

\begin{abstract}
Deformation analysis, one of the main research areas of geodesy, plays an important role for human safety. It is extremely important to determine the horizontal and vertical position changes and deformations due to the movements of the earth's crust and to take preventive measures against possible disasters accordingly. Identifying crustal deformation studies is considered as one of the important issues that scientists are trying to solve. Scientists have to devote a large part of their time to solving this problem. However, the increasing interest in crustal movements and rapid developments in technology have made it necessary to use new software in deformation analysis. Here, a web application has been developed using open source software for static deformation analysis so that expert engineers who are interested in monitoring and analyzing deformations can access evaluation software more easily and make their analysis easier. In this way, every person or institution that wants to organize geodetic data within the scope of $3 D$ deformation analysis and access the results to be obtained from these data quickly, accurately and completely when necessary will benefit from this application. In this context, primarily HTML (Hyper Text Markup Language) and CSS (Cascading Style Sheets) applications were made to create the web platform. In addition, deformation analysis applications were developed with Javascript, one of the client-side programming languages. In order to use this program, first, the ASCII (American Standard Code for Information Interchange) file of the base solutions in a period is obtained from the Leica Geo Office program and transferred to the application. With these base solutions, the periods to be compared in the web application are selected and the deformation analysis is performed. As a result, in this study, the prepared web application will be evaluated with a data set and information about the technical infrastructure of the platform will be given. Thus, a new dimension will be added to the platforms used in deformation analysis and static deformation analysis results that users may need will be presented visually.
\end{abstract}

Keywords: GNSS, Deformation analysis, Open source software 


\section{Giriş}

Son yüzyıldan itibaren insan etkinliklerinin ve gereksinimlerinin artması bilimsel ve teknolojik gelişmelere sebep olmuştur. $\mathrm{Bu}$ gelişmelerin mühendislik alanına yansıması ise; gökdelenler, barajlar, madenler, uzun köprüler, deniz altı karayolu, demir yolu tünelleri şeklinde olmuştur. Ayrıca artan bu sanat yapılarının hareketlerinin izlenmesi de önem kazanmıştır. Teknoloji, bu hareketlerin izlenmesi için jeodezik deformasyon ölçme ve değerlendirme yöntemlerinin gelişmesine de neden olmuştur (Bak, 2014). Günümüzde artık mühendislik ölçmelerinin gayesi tünel, köprü, viyadük gibi büyük sanat yapıları ile depremlerden veya toprak kaymalarından etkilenen bölgeler gibi yerlerin hareketlerini analiz etmek olmuştur (Bayrak \& Yalçınkaya, 2002). Bu kapsamda objedeki şekil, yer vb. değişiklikler deformasyon ölçmeleri ile tespit edilir. Bu ölçmelerin doğru ve eksiksiz olarak yapılması ya da yapılmaması deformasyon analizi sonuçlarına doğrudan yansımaktadır. O nedenle ölçmelerin titizlikle yapılması son derece önemlidir. Dolayısıyla da deformasyon ölçmelerinin analiz sonuçlarının şüpheye yer bırakmayacak şekilde güvenilir olması mühimdir. Mutat anlamda deformasyon analizi, faklı gözlem periyotlarındaki koordinat farklarının istatistiksel olarak karşılaştırılması temeline dayanır (Erdoğan \& Mandalinci, 2019). Statik deformasyon modeli deformasyon analizi modellerinden biridir ve deformasyon vektörlerinin etkiyen kuvvetten ve zaman değişkeninden bağımsız olarak belirlenmesini sağlar (Doğanalp \& Turgut, 2009). Hareketlerin izlenmesi çalışmalarında genellikle statik deformasyon modelleri kullanılmaktadır (Bayrak \& Yalçınkaya, 2002).

İngiliz filozof Francis Bacon’un "bilgi güçtür” sözüyle birlikte bu güce ulaşım hızı artık büyük önem taşımaktadır. Bu çerçevede bilgi teknolojileri önemli rol oynamaktadır. Günbegün hızla gelişen bilgisayar teknolojileri sayesinde her türlü veriyi oluşturmak ve bu verilere ulaşmak mümkün olmaktadır. Bilgi aktarımı için kullanılan platformlar doğru kullanıldıklarında hız ve etkin kullanım sağlanmaktadır. Teknolojinin ilerlemesine paralel olarak internet teknolojisinin gelişmesiyle birlikte araştırma çalışmaları ve bilgi edinme istenilen her yerden belli bir platforma bağlı olmadan yapılabilir hale gelmektedir. Dolayısıyla bu gelişmeler deformasyon analizinde yeni yazılımların kullanılmasını zorunlu kılmış̧ır.

Gelişen teknolojinin etkisiyle GNSS verilerini değerlendirme işlemlerinde gelişmeler yaşanmıştır. Böylece konum belirlemek isteyen kullanıcılara kolaylıklar sunulmaktadır. Bu kapsamda ticari kuruluşlar, üniversiteler, araştırma merkezleri GNSS verilerinin analizleri için web tabanlı çevrimiçi servisler/platformalar geliştirmişlerdir. $\mathrm{Bu}$ servislerin genellikle ücretsiz olması, kullanıcı dostu olması, kullanım için sadece internet bağlantısına ve web tarayıcısına gereksinim duyması ve kullanıcıdan asgari seviyede GNSS bilgisi istemesi bu platformların kullanımlarının geniş ölçüde artmasını sağlamaktadır (Şimşek, Özarpac1, \& Doğan, 2019). GNSS alıcısı ile gerçekleşen ölçmeler sonucunda elde edilen veriler bu servisler/platformlar aracılı̆̆ılla mutlak (PPP) veya rölatif (bağıl) konum çözüm yöntemleriyle değerlendirilebilmektedir. Bu tür GNSS servilerine örnek olarak Online Positioning User Service (OPUS), Australian Online Positioning Service (AUSPOS), Automatic Precise Positioning Service (APPS), Canadian Spatial Reference System Precise Point Positioning (CSRS- PPP), GPS Analysis and Positioning Software (GAPS), MAGIC-GNSS, Trimble RTX verilebilir. Bu tür servislere (Receiver Independent Exchange) RINEX, RINEX2, RINEX3, ASCII, .zip, .gzip, .gz ve hatanaka formatlarında veriler sisteme yüklenebilir. Böylece mutlak veya bağıl çözümlemeler, analizler gerçekleştirilerek gözlem noktalarının yer merkezli koordinatlarına hızlı ve kolay bir şekilde ulaşılabilir (Özdemir, 2022). Bu tür web tabanlı servisler kullanılarak koordinatların cm mertebesinde doğruluk ile elde edilebileceği görülmüştür (Pırtı \& Yazıc1, 2022).

Web tabanlı çevrimiçi değerlendirme servislerince GNSS verilerinin analiz edilmesi hızlı ve kolay bir durum almışken, herhangi bir GNSS veri değerlendirme platformundan elde edilen verilerin yatay ve düşey deformasyon analizi için kullanılması ticari veya akademik yazılımlara bağlı olmaktadır. Bu süreç de analiz işlemlerine ulaşmayı zorlaştırmaktadır. 
$\mathrm{Bu}$ nedenle bu çalışmada deformasyon analizi çalışmalarına kolay ulaşılabilmesi ve bir vizyon oluşturması için GNSS gözlemleri ile periyodik olarak izlenmiş jeodezik ağlarda deformasyonların statik modelle ve S-Transformasyon matrisi yöntemiyle belirlenmesine yönelik geliştirilmiş web tabanlı açık kaynak kodlu bir platform olan "Web-NDefA” hakkında bilgi verilecek ve bir veri grubu ile nasıl değerlendirileceği açıklanacaktır. Böylece bu uygulamanın hayata geçirilmesiyle statik deformasyon analizlerine ihtiyaç duyacak kullanıcılar dünyanın her yerinden saniyeler içinde ilgili web sayfasına ulaşacak ve analizlerini görsel bir şekilde yapacaktırlar. Bu sayede deformasyon analizi hesabında kullanılan platformlara yeni bir boyut kazandırılacaktır.

\section{Deformasyon Analizi Platformu: Web - NDefA}

Bilgiye daha kolay ulaşılması amacıyla ve deformasyon analizi kapsamında jeodezik verileri organize etmek, gerektiğinde bu verilerden elde edilecek sonuçlara hızlı, doğru ve eksiksiz olarak erişmek isteyen her kişi veya kurum tarafindan kullanılabilmesi için internet ortamında bir web uygulaması "Web-NDefA: Web-'N'etwork 'Def'ormation 'A'nalysis" geliştirilmiştir (URL-1). Platform ile GNSS yardımıyla periyodik olarak izlenmiş univaryant dizaynlı jeodezik ağlarda deformasyonların statik modelle belirlenmesi amaçlanmıştır. Leica Geo Office (LGO) yazılımından çıkartılan bir kampanyadaki baz çözüm dosyalarının (ASCII) platforma yüklenmesinden sonra serbest dengeleme, güven ölçütleri, deformasyon analizi, karşılaştırılan periyotlardaki noktaların koordinat farkları, yer değiştirme vektörleri ve bu vektörlerin hata elipsleri işlemleri gerçekleştirilebilir.

Şekil 1'de Web-NDefA platformunun arayüzü ve özellikleri gösterilmiştir. İnternet sayfasının oluşturulması aşamasında işaretleme dili olan HTML ve HTML dokümanının stilini tanımlayan bir dil olan CSS ve web sayfalarının interaktif ve dinamik olmasına olanak sağlayan nesne tabanlı bir betik dil olan Javascript ve kütüphaneleri kullanılmıştır. Bu platform istemci taraflı programlama dilleri ile yazılmış olduğundan çalışma yeri kullanıcıların bilgisayarlarıdır. Bu tür programlama dili komutlarını yorumlayan ve çalıştıran tarayıcılardır. Bu sayede sunucuya fazla yük binmeden, kodlar her istemcinin kendi bilgisayarında çalışırlar. Ayrıca uygulama açık kaynak kodlu yazılımlarla geliştirildiği için istenildiği takdirde geliştirilebilecek esnekliğe sahiptir.

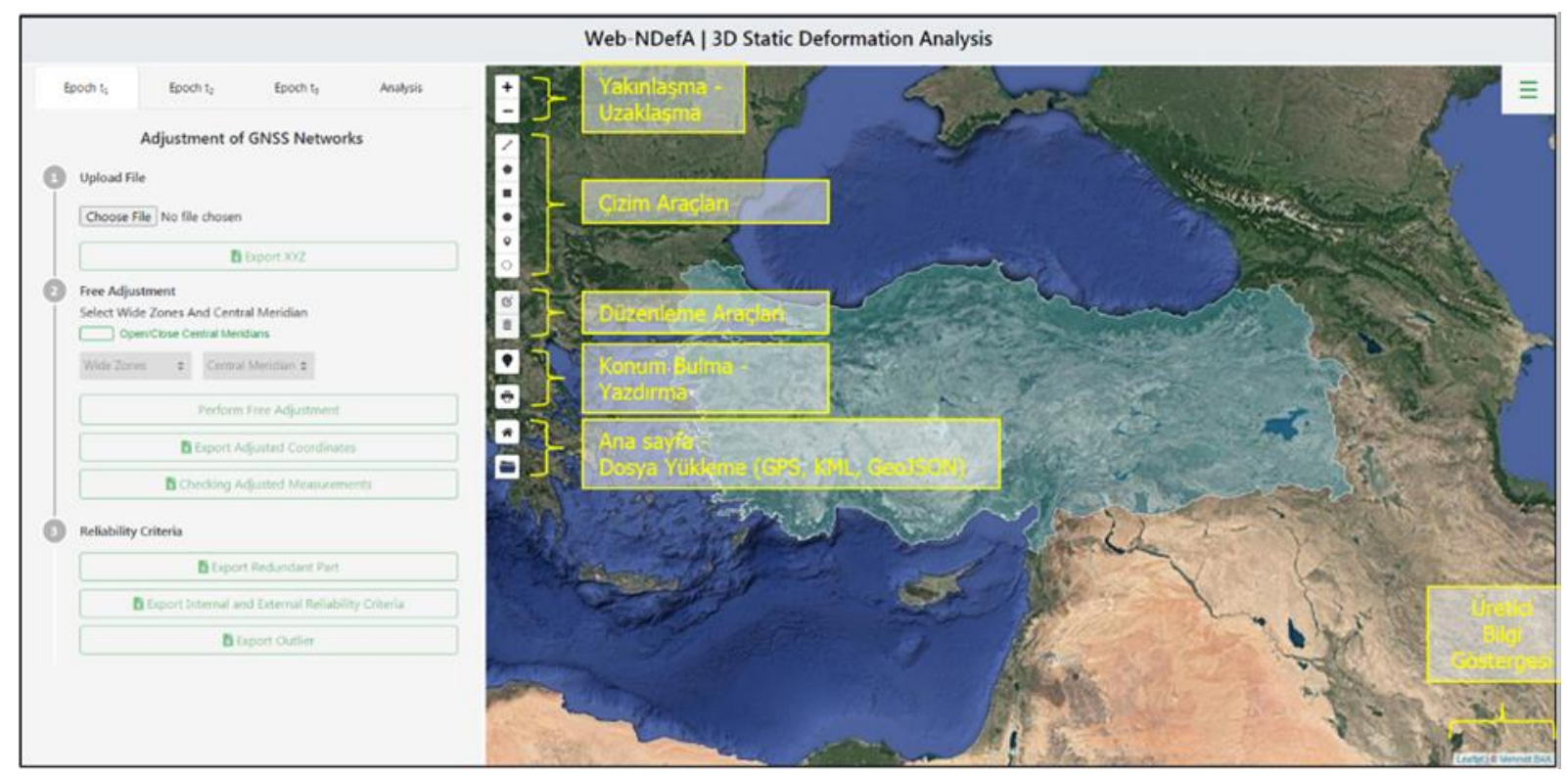

Şekil 1: Web-NDefA kullanıcı arayüzü 
Platformun arayüzüne baktığımızda kullanıcının verilerini yükleyeceği, dengelemenin yapılacağı, analizlerin gerçekleştirileceği, çizim ve düzenleme araçlarının kullanılacağı kısımları görürüz. Bunun yanında arayüzün sağ üst tarafında açılır kapanır pencereyi açmak için kullanılacak buton da görülmektedir. Bu buton yardımıyla aşağıdaki Şekil 2, 3 ve 4 'te görüleceği üzere; harita tabakaları ve bunların opaklık ayarlamaları, Türkiye il ve ilçe sınırları, plaka ve fay hatları ekrana getirilebilir.

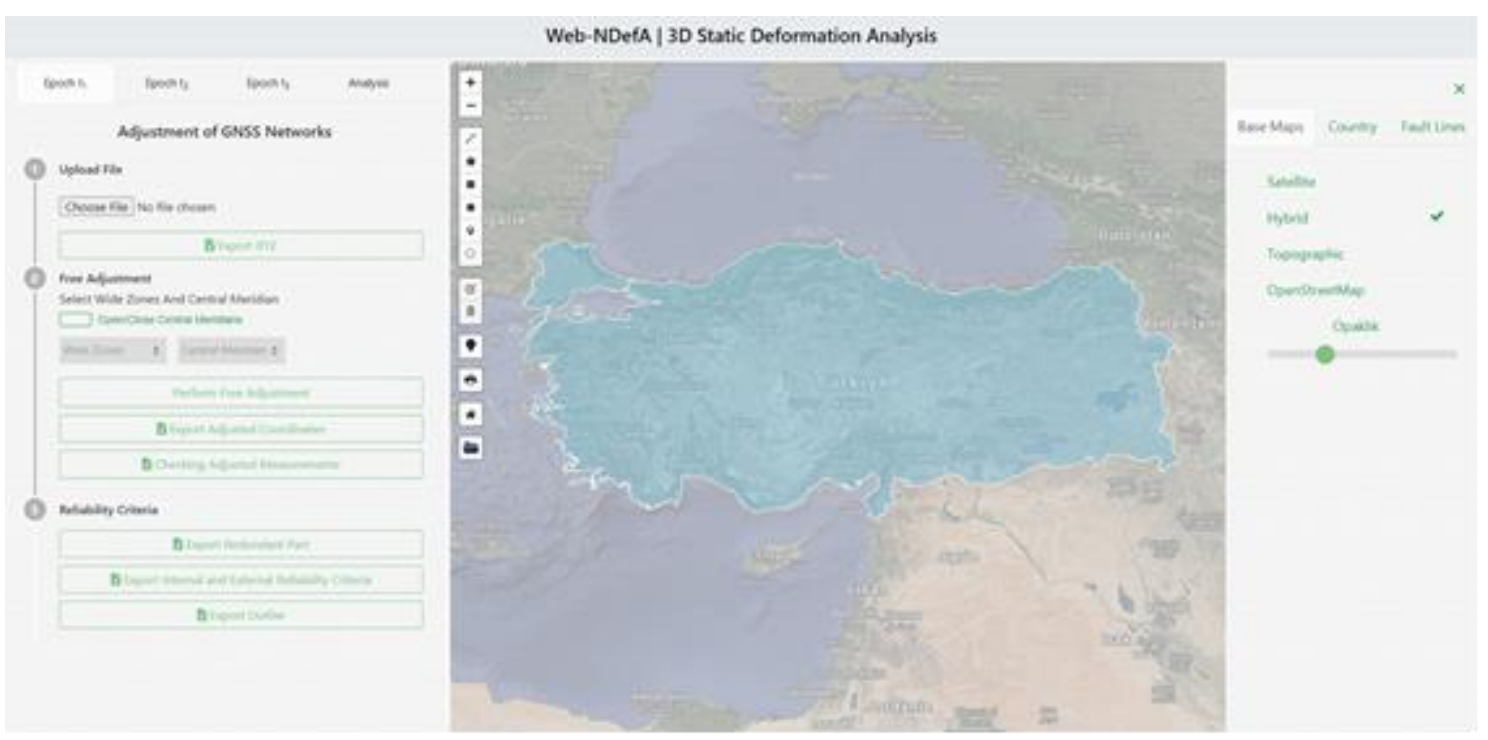

Şekil 2: Harita tabakaları

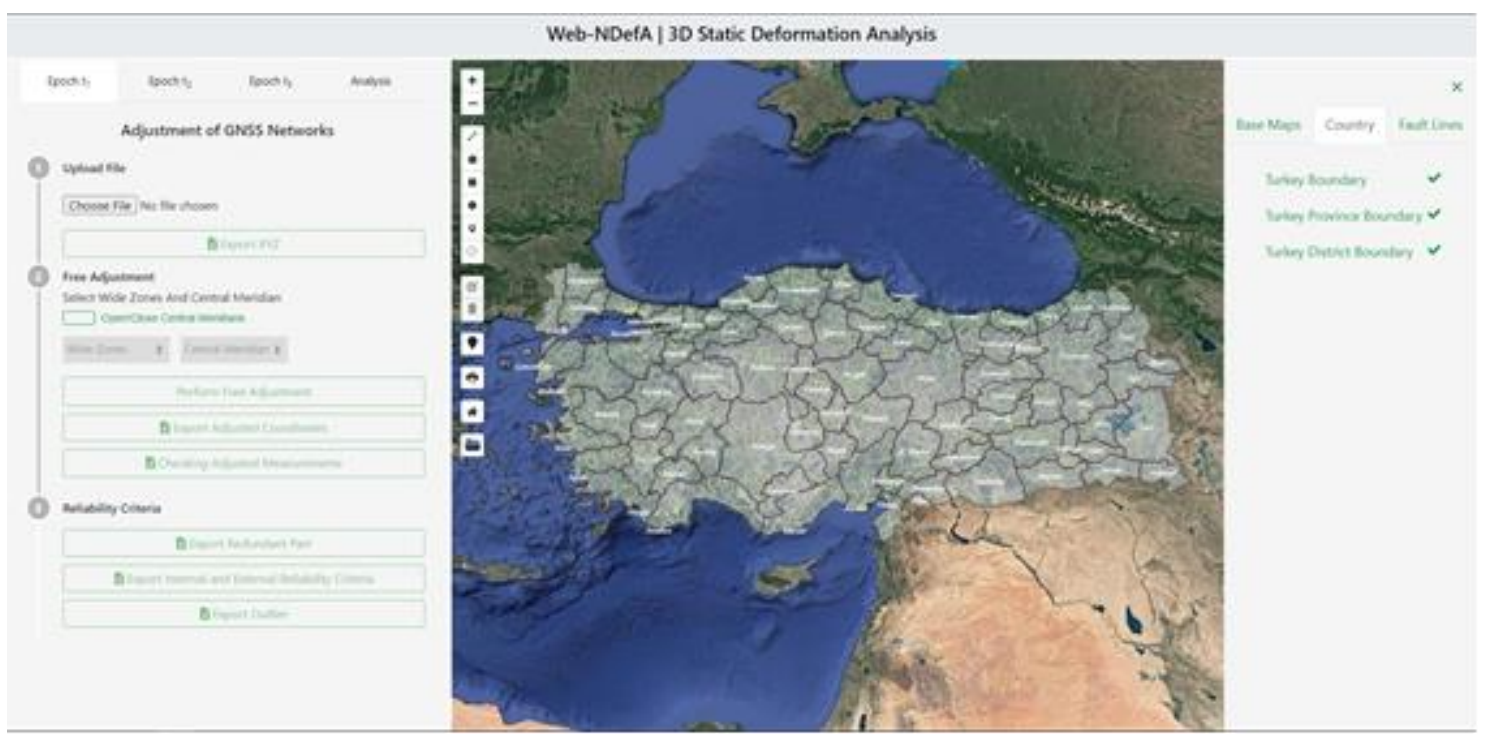

Şekil 3: Türkiye il ve ilçe sınırları 


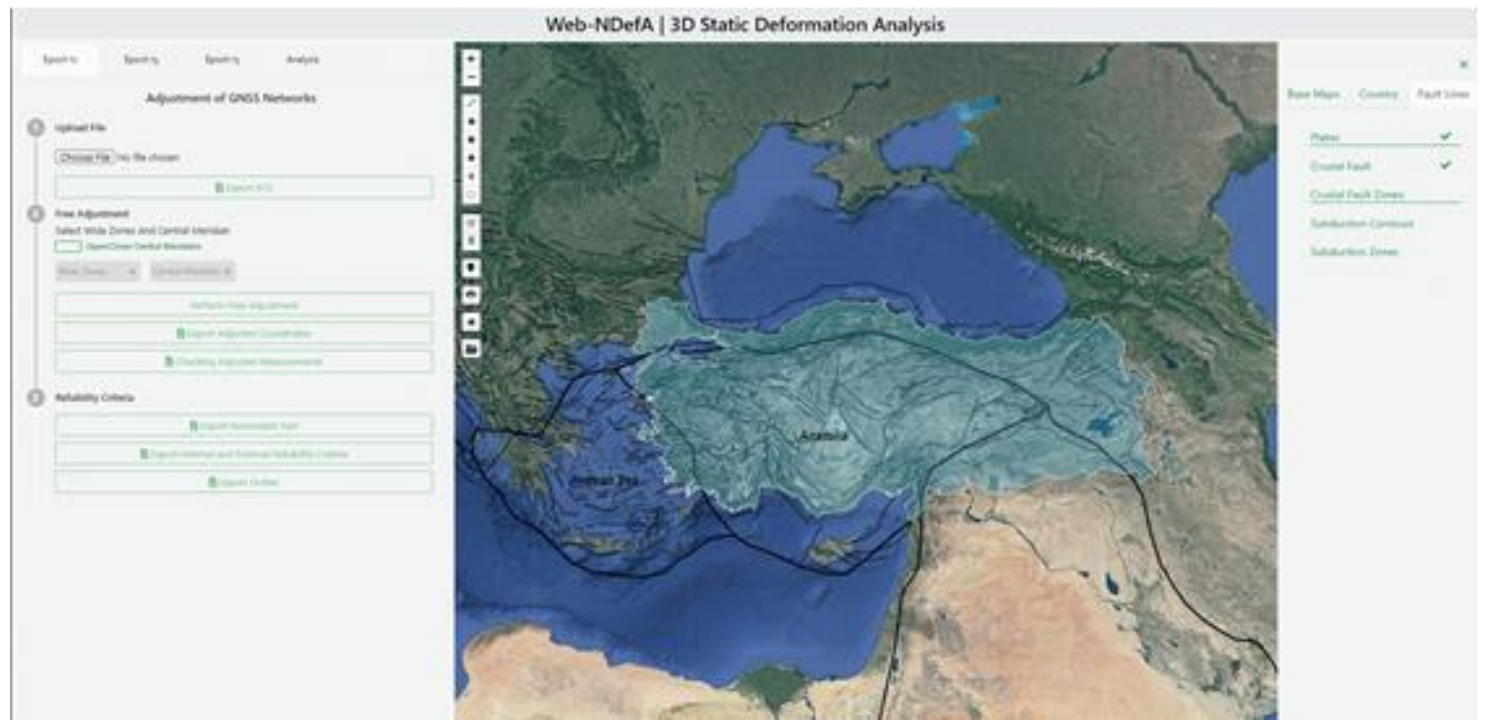

Şekil 4: Plaka ve fay hatları

\subsection{Web-NDefA İş Akış Şeması}

Web-NDefA; dosya yükleme, dengeleme, deformasyon analizi ve yer değiştirme vektörlerini görüntüleme şeklinde temel aşamalardan oluşmaktadır. Genel akış diyagramı aşağıda verilen platform ile deformasyonların izlenmesi görsel bir şekilde yapılacaktır.

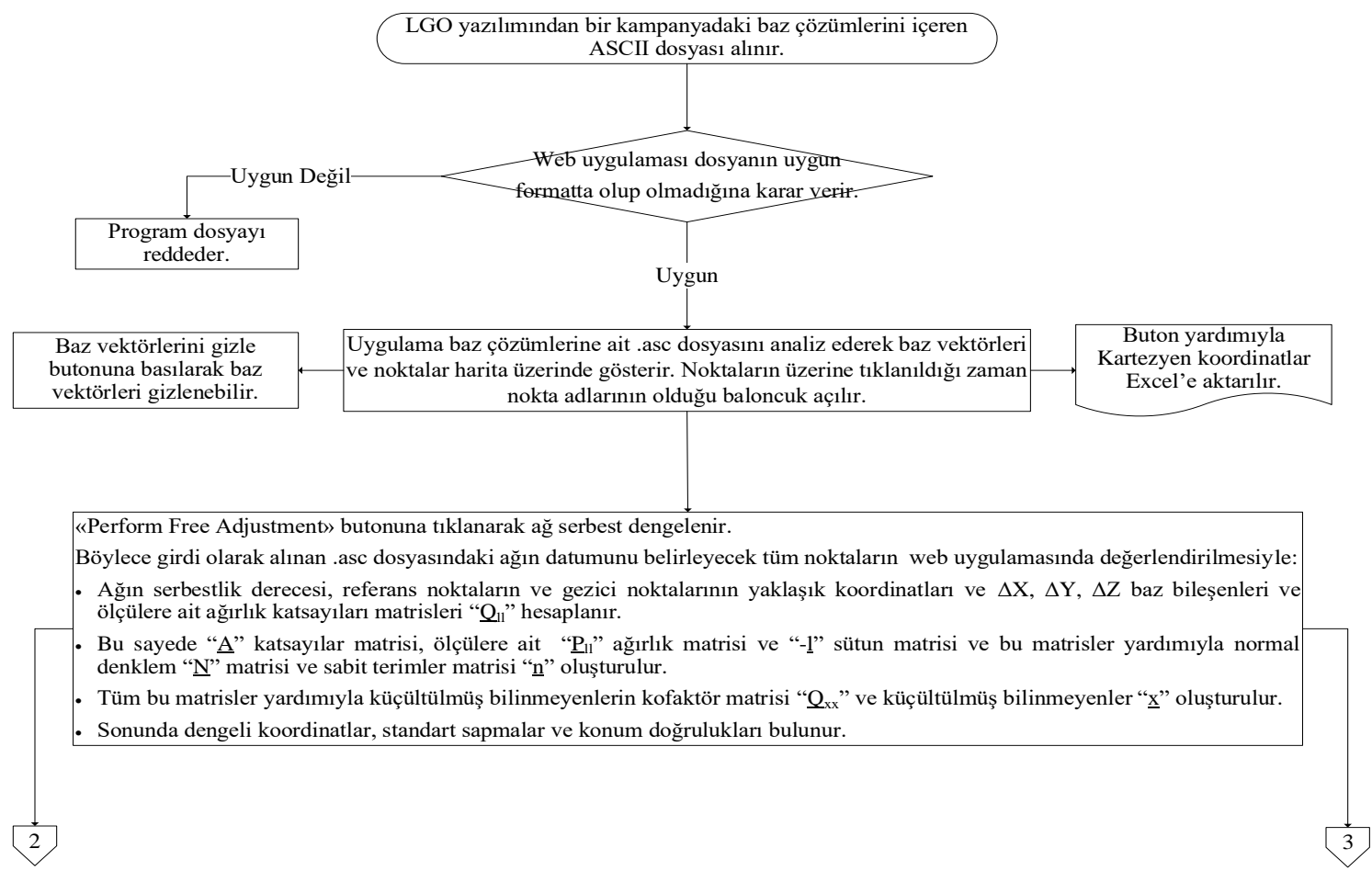

Şekil 5a: Web - NdefA uygulamasında serbest ağ dengelemesi adımının iş akış şeması 


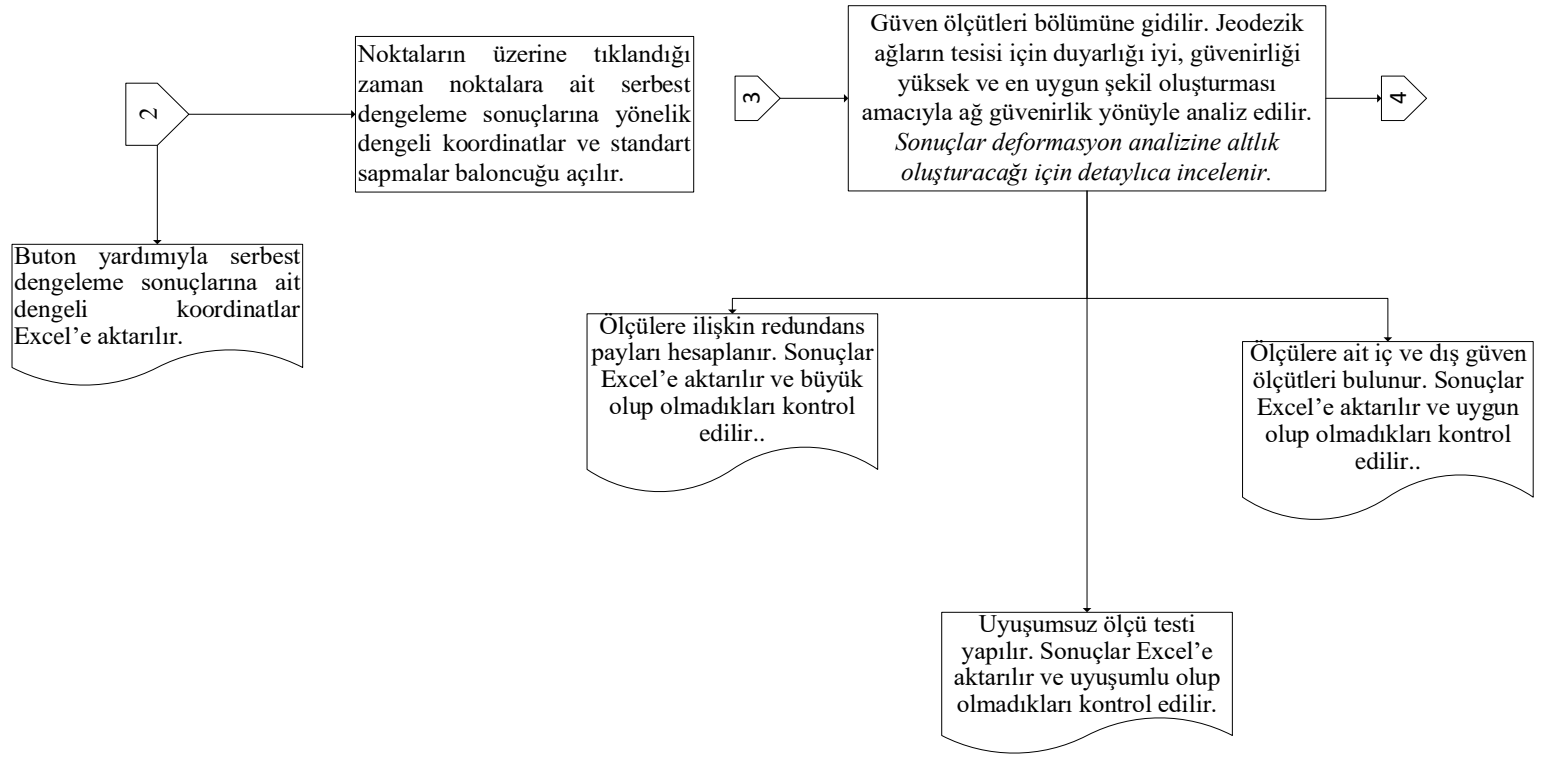

Şekil 5b: Web - NdefA uygulamasında uyuşumsuz ölçü testi adımının akış şeması

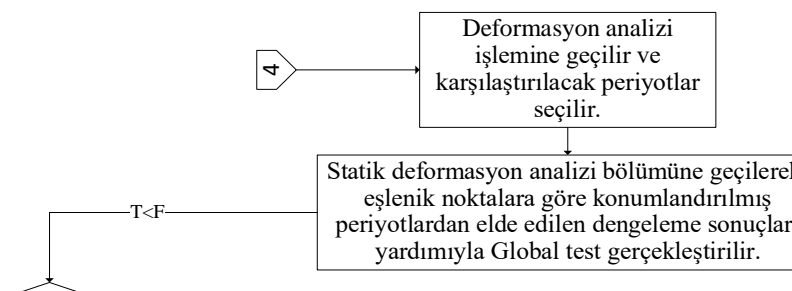

Test büyüklüğü F sınır değerinden küçük çıkması halinde eşlenik noktalara

göre konumlandırılmış periyotlarda deformasyon olmadığına karar verilir.

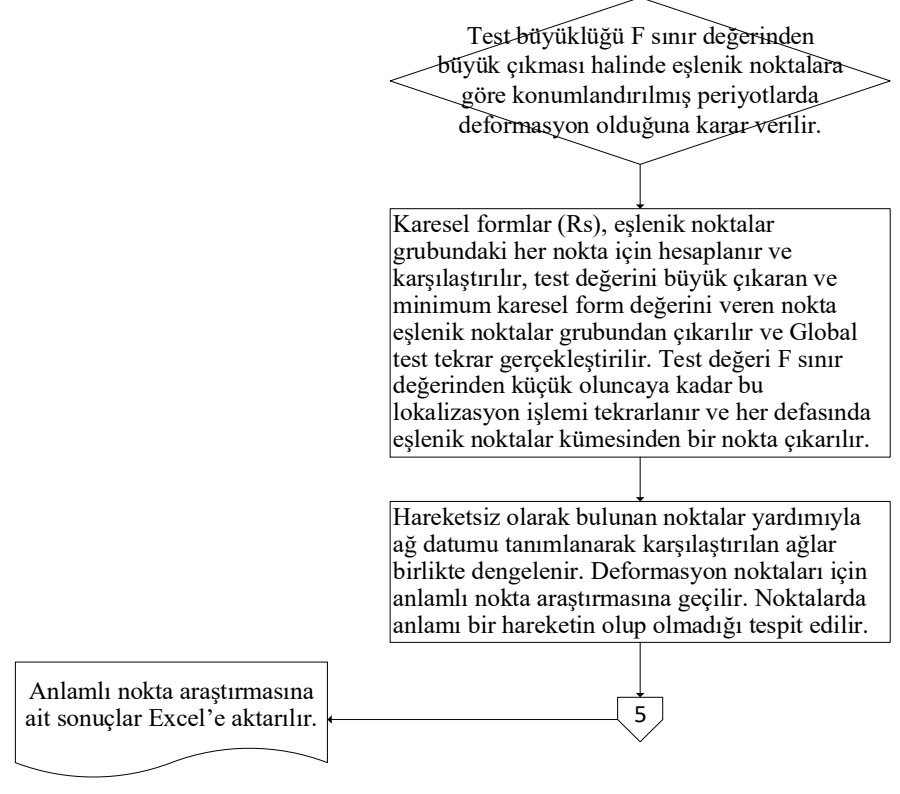

Şekil 5c: Web - NDefA uygulamasında deformasyon analizi ve yerelleştirme adımının iş akış şeması 


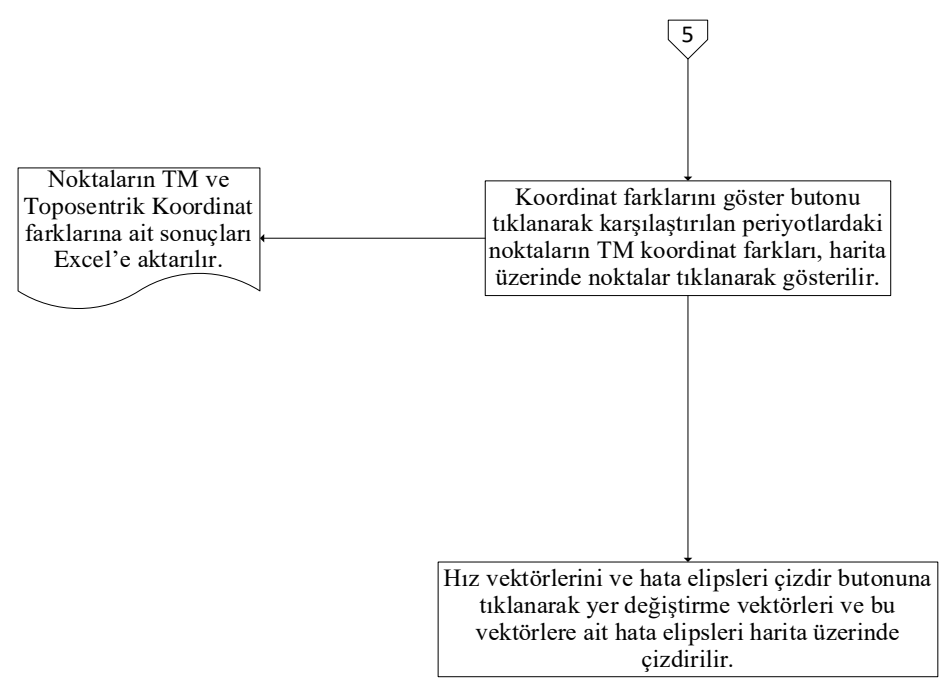

Şekil 5d: Web - NDefA uygulamasında görselleştirme adımına ait iş akış şeması

\section{2 Örnek Bir Uygulama}

Web-NDefA platformunda analiz edilmesi için İstanbul ve yakın bölgesinde bulunan Sürekli Gözlem Yapan GNSS İstasyonlarından IGS, İSKİ-UKBS ve TUSAGA-Aktif noktalarına ait RINEX veriler kullanılmıştır. Verilerin toplandığı epoklar; 05 Ekim 2016 (GPS günü 279) ile 01 Ekim 2019 (GPS günü 274) tarihleridir. 05 Ekim 2016 gününün seçilmesinin nedeni, 30 Eylül 2016 (GPS günü 274) tarihinde Marmara Denizi, Yalova-Çınarcık açıklarında Richter Ölçeği’ne göre Mw = 3.5 büyüklüğünde meydana gelen depremden sonraki bir gün olmasıdır. Aynı şekilde 01 Ekim 2019 (GPS günü 274) gününün seçilmesinin nedeni ise 26 Eylül 2019 (GPS günü 269) tarihinde Marmara Denizinde, Silivri'nin yaklaşık 20-25 kilometre güneyinde ve İstanbul'a 75 kilometre mesafede Richter Ölçeği’ne göre $\mathrm{Mw}=5.7$ büyüklüğünde meydana gelen depremden sonraki bir gün olmasıdır. Böylece bu epoklara ait veriler kullanılarak analizler gerçekleştirilmiş ve platformun nasıl çalıştı̆̆ ortaya konmuştur. Tablo 1'de uygulama için kullanılan noktalar, verilerin toplandığı epoklar ve GPS günleri belirtilmiştir.

Tablo 1: Değerlendirme Grubu

\begin{tabular}{ccc}
\hline Değerlendirme Günü & Nokta Grubu & Değerlendirme Grubu \\
\hline & IGS & ISTA \\
\cline { 2 - 3 } & & TUBI \\
\cline { 2 - 3 } & & BAN1 \\
& & BURS \\
2016-10-05 (DoY: 279) & BILE \\
$\mathbf{2 0 1 9 - 1 0 - 0 1 ( D o Y : ~ 2 7 4 ) ~}$ & & IZMT \\
& & KARB \\
& & SLEE \\
\cline { 2 - 3 } & & KCEK \\
& & PALA \\
& & SILE \\
& & TERK \\
& & TUZL \\
\hline
\end{tabular}

\subsubsection{Dosya Yükleme}

Platforma dosya yüklemek için öncelikle LGO programında IGS, TUSAGA-Aktif ve ISKI-UKBS noktalarına ait RINEX veriler değerlendirilmiş ve ASCII dosyaları elde edilmiştir. Baz çözümleri LGO platformunda 'hassas efemeris (precise 
ephemeris)' verileri değerlendirilerek gerçekleştirilmiştir (Şekil 6). IGS hassas efemeris verileri URL-2 bağlantısıyla elde edilmiştir.

IGS, TUSAGA-Aktif, ISKI-UKBS noktalarına ait RINEX veriler kendi içerisinde değerlendirilmiş ve öncelik ISTA ve TUBI noktalarına verilmiştir. GPS ağında lineer bağımsızlığı sağlamak için 24 saatlik ISTA ve TUBI verileri, tüm noktalara ait verilerin değerlendirileceği kampanyadan bir gün önceki veya bir gün sonraki tarihlerden elde edilmiştir. Bu veriler URL-3 bağlantısıyla indirilmiştir. Bununla beraber kesin koordinatları ITRF 2005 datumunda ve 2005 epoğunda URL-4 adresinden alınan ISTA noktasının koordinatları sabit tutulmuş ve TUBI noktası değerlendirilmiştir. Daha sonra ISTA ve TUBI noktaları referans tutulmak suretiyle TUSAGA-Aktif ve ISKI-UKBS istasyonlarının baz çözümleri gerçekleştirilmiştir. TUSAGAAktif noktalarına ait RINEX veriler URL-5; ISKI-UKBS noktalarına ait RINEX veriler ise URL-6 adresinden indirilmiştir. Ağ tasarımını ve lineer bağımsızlığı optimum düzeyde sağlamak için TUSAGA-Aktif ve ISKI-UKBS noktalarından bazıları referans tutulmak suretiyle değerlendirme aşaması tamamlanmıştır. Epoklar statik deformasyon analizi için birbirleriyle karşılaştırılacak olduğundan ağ geometrilerinin aynı olmasına (univaryant) dikkat edilmiştir. Platformda epok 1 sekmesinde 05 Ekim 2016 tarihinde gerçekleşen kampanya ölçüleri; epok 2 sekmesinde 01 Ekim 2019 tarihinde yapılan kampanya ölçüleri değerlendirilmiş ve analiz aşamasında birbirleriyle karşılaşıııılmıştır.
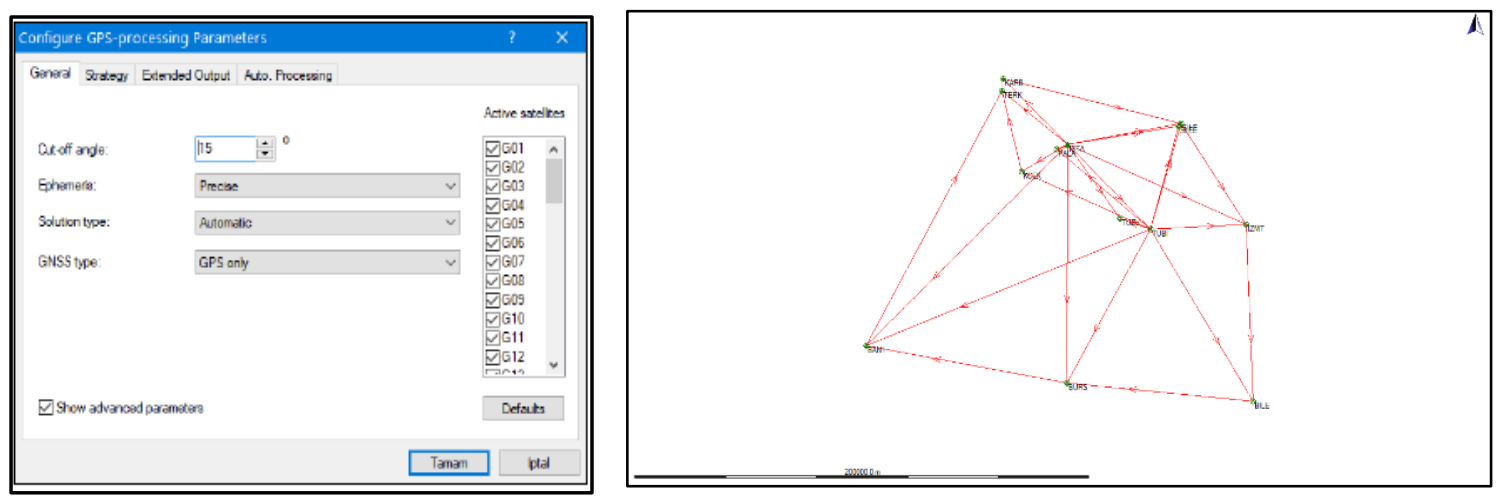

Şekil 6: LGO programında oluşturulan projenin özellikleri (sol) ve baz çözüm kanavası (sağ)

Değerlendirme işlemleri neticesinde LGO programından ASCII formatında baz çözüm dosyası elde edilir. Şekil 7'de örnek bir baz çözüm dosyası gösterilmiştir. Bu baz çözüm dosyası platformumuza girdi olarak yüklenecek dosyadır.

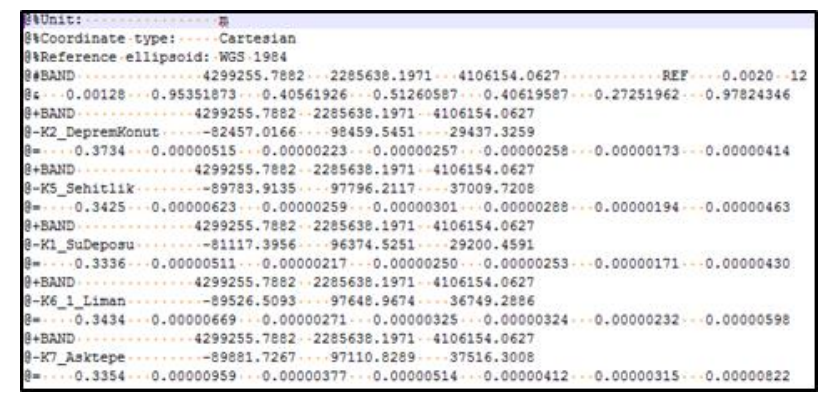

Şekil 7: Leica Geo Office programından ASCIl formatında elde edilen baz çözümleri

Platformun ana sayfasında "Upload File" kısmında yer alan "Choose File" sekmesi kullanılarak ASCII formatındaki baz çözümlerine ait dosya sisteme yüklenir. Dosya yüklendikten sonra noktalar ve baz vektörleri harita üzerine gelir (Şekil 8) ve "Export XYZ” butonu yardımıyla kartezyen koordinatları .xls formatında dışarıya aktarılabilir. Harita üzerine gelen baz vektörleri ve noktalar istenildiği zaman gizlenir/gösterilir. 


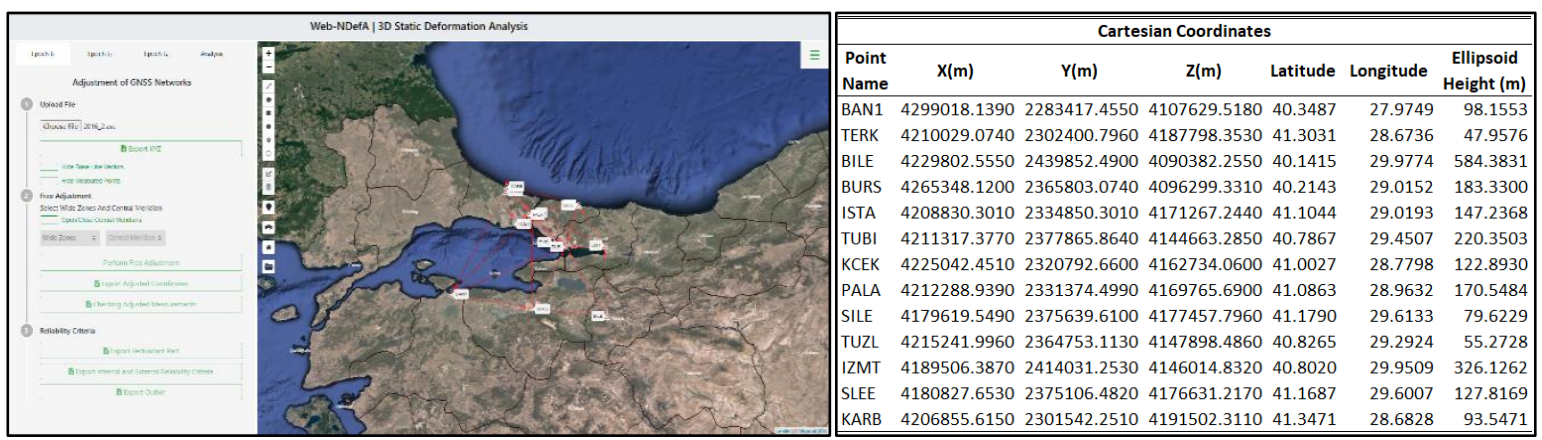

Şekil 8: Web - NDefA uygulamasında baz çözüm kanavası (sol) ve .xls formatında kartezyen koordinat tablosu (sağ)

\subsubsection{Serbest Ağ Dengelemesi İşlemi}

Tüm nokta koordinatları bilinmeyen olarak ele alınan ağların dengelenmesine serbest ağ dengelemesi denilir. Normal denklem katsayıları matrisi singüler olduğundan determinantı sıfırdır. Serbest datum parametreleri defekt sayısına (rank bozukluğuna) eşittir. Datum seçimine bağlı olarak nokta doğrulukları ve konumlarının değişmesinin yanında ağ geometrisi değişmez. Bunun yanında posterior (sonsal) varyans $\left(\mathrm{s}_{0}{ }^{2}\right)$, dengelenmiş ölçüler ve bunların ve fonksiyonlarının standart sapması değişmez (Demirel, 2009). Ayrıca dengeleme hesabında uygulanan Gauss Markov modelinde n sayıda gözlem, $\mathrm{m}$ sayıda bilinmeyen parametre ile gözlem hatalarının ya da başka bir başka ifadeyle istatistiksel olarak ölçülere getirilecek düzeltmelerin kareleri ağırlıklandııılmış toplamının minimum olması esas alınır (Akyılmaz, Acar, \& Özlüdemir, 2007).

Bu kapsamda baz çözümleri platforma yüklenir ağın serbest dengelenmesi için önce dilim genişliği ve dilim orta meridyeni seçilir. Bu seçime yardımcı olması amacıyla "Free Adjustmet" kısmında yer alan "Open/Close Central Meridian" sekmesi yardımıyla harita üzerine dilim orta meridyenleri getirilerek dilim genişliği ve dilim orta meridyen seçim işlemi kolaylaştırılır (Şekil 9).

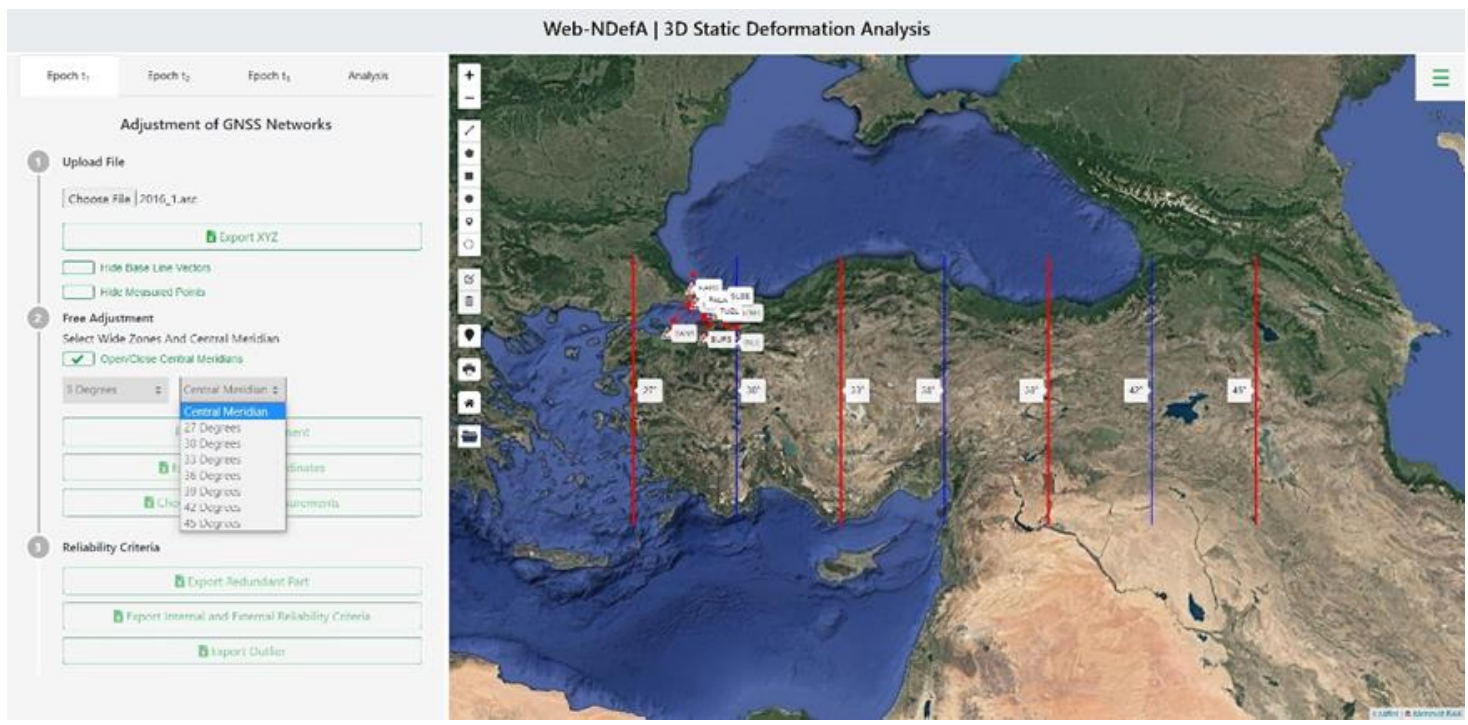

Şekil 9: Dilim genişliği ve dilim orta meridyen seçim işlemi

Dilim genişliği ve dilim orta meridyeni seçildikten sonra "Perform Free Adjustment" butonu yardımıyla ağ serbest olarak dengelenir. İlgili butonlar yardımıyla dengelenmiş sonuçlar .xls formatında dışarıya aktarılabilir (Şekil 10) ve dengelemenin denetimi yapılabilir (Şekil 11). 


\begin{tabular}{|c|c|c|c|c|c|c|c|c|c|c|c|}
\hline \multicolumn{12}{|c|}{ Adjusted Coordinates and Mean Errors } \\
\hline $\begin{array}{l}\text { Point } \\
\text { Name }\end{array}$ & $X(m)$ & $Y(m)$ & $z(m)$ & $m \times(m)$ & $m y(m)$ & $\mathrm{mz}(\mathrm{m})$ & Latitude & Longitude & $\begin{array}{c}\text { Ellipsoid } \\
\text { Height } \\
\text { (m) }\end{array}$ & Easting (m) & Northing (m) \\
\hline BAN1 & 4299018.1352 & 2283417.4531 & 4107629.5148 & 0.0017 & 0.0012 & 0.0016 & 40.3487 & 27.9749 & 98.1503 & 327949.4140 & 4470211.5310 \\
\hline TERK & 4210029.0844 & 2302400.8023 & 4187798.3652 & 0.0032 & 0.0022 & 0.0029 & 41.3031 & 28.6736 & 47.9746 & 388912.6570 & 4575080.1000 \\
\hline BILE & 4229802.5557 & 2439852.4904 & 4090382.2544 & 0.0020 & 0.0014 & 0.0019 & 40.1415 & 29.9774 & 584.3828 & 498073.1370 & 4445236.4850 \\
\hline BURS & 4265348.1167 & 2365803.0720 & 4096299.3276 & 0.0017 & 0.0011 & 0.0015 & 40.2143 & 29.0152 & 183.3246 & 416169.0850 & 4453783.9720 \\
\hline ISTA & 4208830.2944 & 2334850.2966 & 4171267.2379 & 0.0010 & 0.0007 & 0.0009 & 41.1044 & 29.0193 & 147.2267 & 417621.8470 & 4552636.2050 \\
\hline TUBI & 4211317.3765 & 2377865.8647 & 4144663.2834 & 0.0010 & 0.0007 & 0.0009 & 40.7867 & 29.4507 & 220.3493 & 453634.3410 & 4517033.9040 \\
\hline KCEK & 4225042.4458 & 2320792.6567 & 4162734.0553 & 0.0020 & 0.0014 & 0.0018 & 41.0027 & 28.7798 & 122.8856 & 397337.2930 & 4541595.6720 \\
\hline PALA & 4212288.9340 & 2331374.4957 & 4169765.6849 & 0.0020 & 0.0014 & 0.0019 & 41.0863 & 28.9632 & 170.5407 & 412881.9860 & 4550678.0020 \\
\hline SILE & 4179619.5524 & 2375639.6121 & 4177457.7991 & 0.0014 & 0.0010 & 0.0014 & 41.1790 & 29.6133 & 79.6277 & 467554.6030 & 4560523.9740 \\
\hline TUZL & 4215241.9940 & 2364753.1127 & 4147898.4840 & 0.0020 & 0.0014 & 0.0019 & 40.8265 & 29.2924 & 55.2700 & 440314.0480 & 4521546.2490 \\
\hline IZMT & 4189506.3866 & 2414031.2532 & 4146014.8305 & 0.0015 & 0.0010 & 0.0014 & 40.8020 & 29.9509 & 326.1252 & 495859.4080 & 4518583.7690 \\
\hline SLEE & 4180827.6494 & 2375106.4793 & 4176631.2130 & 0.0020 & 0.0014 & 0.0019 & 41.1687 & 29.6007 & 127.8108 & 466489.0860 & 4559388.4960 \\
\hline KARB & 4206855.6303 & 2301542.2597 & 4191502.3287 & 0.0025 & 0.0018 & 0.0023 & 41.3471 & 28.6828 & 93.5723 & 389756.8980 & 4579960.6000 \\
\hline
\end{tabular}

Şekil 10: Serbest ağ dengelemesinin .xıs formatında sonuç çıktısı

\begin{tabular}{|c|c|c|c|c|}
\hline \multicolumn{5}{|c|}{ Checking Adjusted Measurements } \\
\hline Point Name & Adjusted Baseline Components & Adjusted Coordinate Differences & Difference & Check \\
\hline BAN1 - TERK $(\Delta \mathrm{X})$ & -88989.05077 & -88989.05077 & 0.000000 & Ok. \\
\hline BAN1 - TERK $(\triangle Y)$ & 18983.34926 & 18983.34926 & 0.000000 & Ok. \\
\hline BAN1 - TERK $(\Delta Z)$ & 80168.85036 & 80168.85036 & 0.000000 & Ok. \\
\hline BILE - BURS $(\Delta \mathrm{X})$ & 35545.56104 & 35545.56104 & 0.000000 & Ok. \\
\hline BILE - BURS $(\Delta Y)$ & -74049.41837 & -74049.41837 & 0.000000 & Ok. \\
\hline BILE - BURS $(\Delta Z)$ & 5917.073212 & 5917.073212 & 0.000000 & Ok. \\
\hline BURS - BAN1 $(\Delta \mathrm{X})$ & 33670.01852 & 33670.01852 & 0.000000 & Ok. \\
\hline BURS - BAN1 ( $\triangle Y)$ & -82385.61893 & -82385.61893 & 0.000000 & Ok. \\
\hline BURS - BAN1 ( $\Delta \mathrm{Z})$ & 11330.18718 & 11330.18718 & 0.000000 & Ok. \\
\hline
\end{tabular}

Şekil 11: Dengelemenin denetiminin .xıs formatında sonuç çıktısı

\subsubsection{Güven Ölçütleri}

Yatay ve düşey yöndeki deformasyonları takip etmek için oluşturulan jeodezik ağlardan belli bir hata olasıllı̆̆ içinde yer değiştirmeleri ortaya çıkartması beklenir. Ağlardan duyarlılık açısından olabildiğince homojen olmaları beklenir. Ağın niteliğini gösteren duyarlık ölçütleri, geçerli bir dengeleme modeli ile gerçekleştirilen hesaplamalar neticesinde elde edilirse gerçekçi olurlar. Dolayısıyla ağın güvenilir olması için ağın geometrik şekli model hatalarını ortaya çıkartabilmelidir. Belli bir amaç için kurulan jeodezik bir ağın duyarlık ve güven açısından uygun olup olmadığı duyarlık ve güven ölçütleri ile tespit edilir. Bu kapsamda platformda serbest dengelemesi yapılmış ağdaki ölçülere ait güven ölçütleri "Reliability Criteria" kısmında yer alan ilgili butonlar kullanılarak öğrenilebilir. Web uygulaması, ağdaki ölçüleri kaba hatalar bakımından kontrol edilebilirlik derecesi olan redundans paylarına (r) göre değerlendirir. Eğer ölçülerin redundans payları (r); $0-0.10$ aralığında ise değerlendirme zayıf $(r=0-0.10$, Zayıf), $0.10-0.30$ aralığında ise değerlendirme yeterli $(r=0.10-0.30$, Yeterli), 0.30 - 1.00 aralığında ise değerlendirme iyi (Ok.) $(r=0.30-1.00$, İyi) şeklinde gösterilir (Şekil 12). Bununla birlikte uygulama/platform, bir ölçüdeki hatanın açığa çıkarılabilmesi için en az ne büyüklükte bir değere ulaşması gerektiğini gösteren iç güven ölçütlerini ve hataların koordinatlara olan etkisini gösteren dış güven ölçütlerini de hesaplar. İç güven ölçütleri bir ölçünün standart sapmasına ( $\sigma_{i}^{\prime}$ ye) bağlıdır ve uygulama bir ölçünün iç güven ölçütünü $(6-8) \sigma_{i}$ değer aralığında hesaplarsa iyi denetlenebilir (Ok.) olarak yorumlar. Ölçülerin dış güvenirlikleri ( 8 - 10) değer aralığının altında ise uygulama bu değerleri dış güvenirlik yüksek (Ok.) olarak yorumlar (Şekil 13). Ayrıca uygulama ile uyuşumsuz ölçüler de belirlenir. Böylece kaba hatalar fark edilebilir. Uyuşumsuz ölçülerin belirlenmesi için Pope Test yöntemi kullanılır ve yanılma olasılı̆̆ 1 $\% 5$ seçilir. Her bir ölçü için test büyüklükleri hesaplanır ve F tablo değeri belirlenen güven sınırı ile karşılaştırılır. Test büyüklüğü güven sınıının alınnda kalırsa uygulama (Ok.) şeklinde yorumlar (Şekil 14).(Yalçınkaya, Teke, \& Bayrak, 2003). 
Bu veriler .xls formatında dışarıya aktarılır. Böylece ağın kalitesi ve kullanıma uygunluğu irdelenir.

\begin{tabular}{|lcc|}
\hline \multicolumn{1}{|c}{ Base Vectors } & Redundant Parts & \\
\hline BA & Comment \\
BAN1 - TERK $(\Delta \mathrm{X})$ & 0.845206916 & Ok. \\
BAN1 - TERK $(\Delta \mathrm{Y})$ & 0.812525513 & Ok. \\
BILE - BURS $(\Delta \mathrm{X})$ & 0.833696743 & Ok. \\
BILE - BURS $(\Delta \mathrm{Y})$ & 0.799190114 & Ok. \\
BILE - BURS $(\Delta Z)$ & 0.778045178 & Ok. \\
BURS - BAN1 $(\Delta \mathrm{X})$ & 0.790522673 & Ok. \\
BURS - BAN1 $(\Delta Y)$ & 0.520804823 & Ok. \\
BURS - BAN1 $(\Delta Z)$ & 0.51127661 & Ok. \\
ISTA - TUBI $(\Delta \mathrm{X})$ & 0.526546168 & Ok. \\
ISTA - TUBI $(\Delta Y)$ & 0.804581802 & Ok. \\
ISTA - TUBI $(\Delta Z)$ & 0.814093903 & Ok. \\
ISTA - KCEK $(\Delta X)$ & 0.808153093 & Ok. \\
ISTA - KCEK $(\Delta Y)$ & 0.438194771 & Ok. \\
ISTA - KCEK $(\Delta Z)$ & 0.432402897 & Ok. \\
ISTA - PALA $(\Delta X)$ & 0.460359602 & Ok. \\
ISTA - PALA $(\Delta Y)$ & 0.424794219 & Ok. \\
\hline
\end{tabular}

Şekil 12: Redündans paylarının .xıs formatında sonuç çıktısı

\begin{tabular}{|lcccc|}
\hline \multicolumn{5}{|c}{ Internal and External Reliability Criteria } \\
\hline \multicolumn{1}{|c}{ Base Vectors } & Internal Reliability Criteria & Comment & $\begin{array}{c}\text { External Reliability } \\
\text { Criteria }\end{array}$ & Comment \\
\hline BAN1 - TERK $(\Delta \mathrm{X})$ & 0.017639586 & Ok & 1.767438485 & Ok \\
BAN1 - TERK $(\Delta Y)$ & 0.012503851 & Ok & 1.983821693 & Ok \\
BAN1 - TERK $(\Delta Z)$ & 0.016324859 & Ok & 1.844575248 & Ok \\
BILE - BURS $(\Delta X)$ & 0.011966277 & Ok & 2.070224979 & Ok \\
BILE - BURS $(\Delta Y)$ & 0.008448797 & Ok & 2.205870109 & Ok \\
BILE - BURS $(\Delta Z)$ & 0.011198329 & Ok & 2.125990888 & Ok \\
BURS - BAN1 $(\Delta X)$ & 0.011682373 & Ok & 3.961583117 & Ok \\
BURS - BAN1 $(\Delta Y)$ & 0.007973238 & Ok & 4.03788226 & Ok \\
BURS - BAN1 $(\Delta Z)$ & 0.010768179 & Ok & 3.916252108 & Ok \\
ISTA - TUBI $(\Delta X)$ & 0.005888471 & Ok & 2.035389128 & Ok \\
ISTA - TUBI $(\Delta Y)$ & 0.004079284 & Ok & 1.973602184 & Ok \\
ISTA - TUBI $(\Delta Z)$ & 0.005517104 & Ok & 2.01224396 & Ok \\
ISTA - KCEK $(\Delta X)$ & 0.013165759 & Ok & 4.676375158 & Ok \\
ISTA - KCEK $(\Delta Y)$ & 0.009145536 & Ok & 4.731794105 & Ok \\
ISTA - KCEK $(\Delta Z)$ & 0.011998457 & Ok & 4.471504536 & Ok \\
\hline \hline
\end{tabular}

Şekil 13: lç ve dış güven ölçütlerinin .xls formatında sonuç çıktısı

\begin{tabular}{|lcc|}
\hline \hline \multicolumn{3}{|c|}{ Confidence Limit for POPE Test 1.9507743527760348 and Total Probability of Error: $\mathbf{5 \%}$} \\
\hline \multicolumn{1}{c}{ Base Vectors } & Outlier Test & \\
\hline ISTA - KCEK $(\Delta \mathrm{X})$ & 0.72519584 & Result \\
ISTA - KCEK $(\Delta Y)$ & 0.25283421 & Ok. \\
ISTA - KCEK $(\Delta Z)$ & 0.34671384 & Ok. \\
ISTA - PALA $(\Delta X)$ & 0.47942371 & Ok. \\
ISTA - PALA $(\Delta Y)$ & 0.00795392 & Ok. \\
ISTA - PALA $(\Delta Z)$ & 0.19438298 & Ok. \\
ISTA - SILE $(\Delta X)$ & 0.03694275 & Ok. \\
ISTA - SILE $(\Delta Y)$ & 0.13840569 & Ok. \\
ISTA - SILE $(\Delta Z)$ & 0.73668496 & Ok. \\
ISTA - TUZL $(\Delta X)$ & 0.98714331 & Ok. \\
ISTA - TUZL $(\Delta Y)$ & 0.98025835 & Ok. \\
ISTA - TUZL $(\Delta Z)$ & 0.90926224 & Ok. \\
\hline
\end{tabular}

Şekil 14: Uyuşumsuz ölçüler testinin .xıs formatında sonuç çıktısı

\subsubsection{Statik Deformasyon Analiz İşlemi}

Belirli bir zaman aralığında meydana gelen deformasyonları tespit etmek ve irdelemek için kullanılan statik deformasyon modelinde kontrol ağlarındaki noktaların kararlılıkları, zamandan ve etkiyen kuvvetlerden bağımsız olarak ele alınır. Bu modelde kontrol ağlarındaki noktalarda belirli periyotlarda gözlemler yapılır. Her periyotta gözlemlenen ölçüler ayrı ayrı serbest dengelenir, koordinat farkları hesaplanır ve istatistik test yöntemleri uygulanarak deformasyon irdelemesi 
gerçekleştirilir. Ağlarda noktaların ölçüm süreci boyunca sabit kaldıkları kabul edilir. Bu çerçevede statik model, jeodezik deformasyon ölçmelerinin analizinde en çok uygulanan modeldir (Yalçınkaya, 2019). Bir jeodezik ağda $t_{1}$ ve $t_{2}$ epoklarında gerçekleştirilen ölçmelerin i ve j gibi farklı datumlarda serbest ağ dengelemesi modeline göre dengelenmesinden sonra ortak bir k datumuna veya i ve j datumlarının birbirleri arasındaki geçişi için Baarda tarafından 1950’lerde gerçekleştirilen STransformasyonu yöntemi kullanılır (Başkaya, 1995; Caspary \& Rueger, 1987; Demirel, 1987; Welsch, 1993). Bu yöntemde yeni bir dengeleme hesabı lüzumlu değildir. Datum dönüşümünde faydalı olan bu yöntem ayrıca; karşılaştırılan iki periyottaki jeodezik ağda bir deformasyon olup olmadığını öğrenmek için gerçekleştirilen global test hesaplamalarında, eğer ağda deformasyon varsa birbirinin ardı sira yinelenerek uygulanmasiyla karesel formun hesaplanmasında ve deformasyon noktalarının yerelleştirilmesinde ve neticesinde sabit ve hareketli noktaların tespit edilip ortaya çıkartılmasında kullanılır. (Baarda, 1973; Bak, 2014; van Hees, 1982). İki periyotlu analiz işlemlerinde, $\mathrm{t}_{1}$ ve $\mathrm{t}_{2}$ periyotlarının ortak $\mathrm{k}$ datumundaki koordinat bilinmeyenleri $\left(\boldsymbol{x}_{m}^{k}\right)_{1},\left(\boldsymbol{x}_{m}^{k}\right)_{2},\left(\boldsymbol{Q}_{m m}^{k}\right)_{1}$ ve $\left(\boldsymbol{Q}_{m m}^{k}\right)_{2}$ kofaktör matrisleri elde edilir. Eşlenik noktalar ile ortak bir k datumunda tanımlanmış jeodezik ağda bir hareket olup olmadığı global test ile tespit edilir. Nokta koordinatlarındaki değişimleri incelemek için sıfır hipotezi ve T test büyüklüğü belirlenir (Caspary \& Rueger, 1987; Gründig, Neureither, \& Bahndorf, 1985; Pelzer, 1971; van Mierlo, 1981). F tablo değeri de $\mathrm{F}_{\mathrm{hm}, \mathrm{f}, 1-\alpha}$ olarak hesaplanır. Test değeri (T) eğer tablo değerinden (F) büyük çıkarsa, eşlenik noktalara göre konumlandırılmış ağın datum noktalarının birinde veya birçoğunda anlamlı hareketlilik olduğu sonucuna varılır (Erol, 2008). Global test neticesinde ağın herhangi bir yerinde deformasyon olduğu belirlenmiş ise, noktalara ait yerelleştirme işlemlerinin yapılarak sabit/sabit olmayan noktaları belirlenir sabit olamayan noktaların konumlarındaki hareketin anlamlı (significant) olup olmadığının tespit edilmesine geçilir.

Geliştirilen platformda bu işlemler ilk önce karşılaştırılacak epoklar seçilerek (Şekil 15), sonrasında ise sırasıyla; global test (Şekil 16), hareketsiz datum noktalarının bulunması (Şekil 17) ve hareketli bulunan noktalar için anlamlılık testi (Şekil 18) ve bu test sonucunun .xls formatında dışarıya aktarılması (Şekil 19) ile gerçekleştirilir. Deformasyon analizi işlemlerinden sonra karşılaştırılan noktaların hem UTM/TM hem de yerel/toposentrik koordinat farkları hesaplatılır, noktalar üzerinde bir baloncuk açılarak baloncuğa yazdırılır (Şekil 20) ve .xls formatında dışarıya aktarılır (Şekil 21). Ayrıca noktalara ait yer değiştirme vektörleri ve bunların hata elipsleri de harita üzerine ölçekli çizdirilerek (Şekil 22) deformasyon hızlarına ait görsel bir inceleme işlemi de sağlanmış olur.

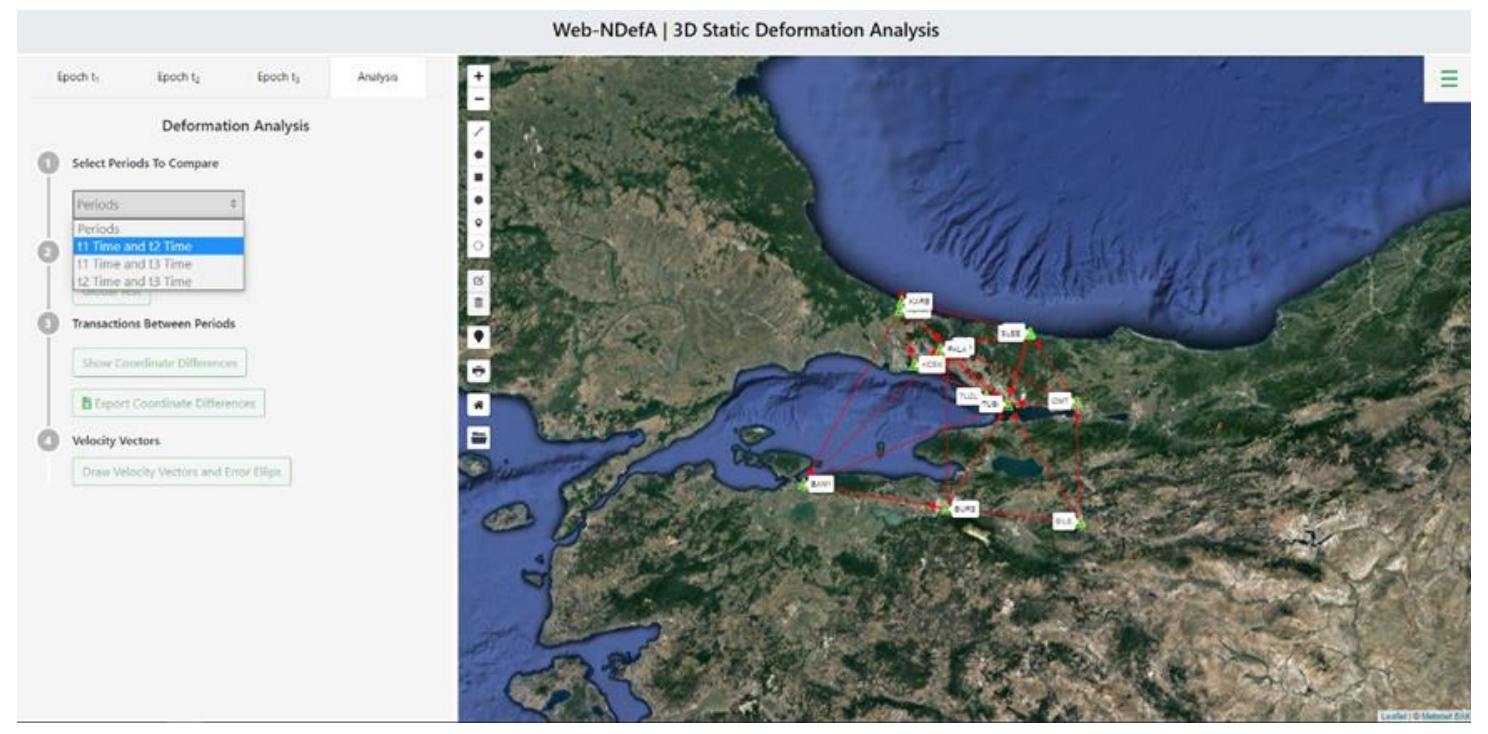

Şekil 15: Karşılaştırılacak epokların seçimi 


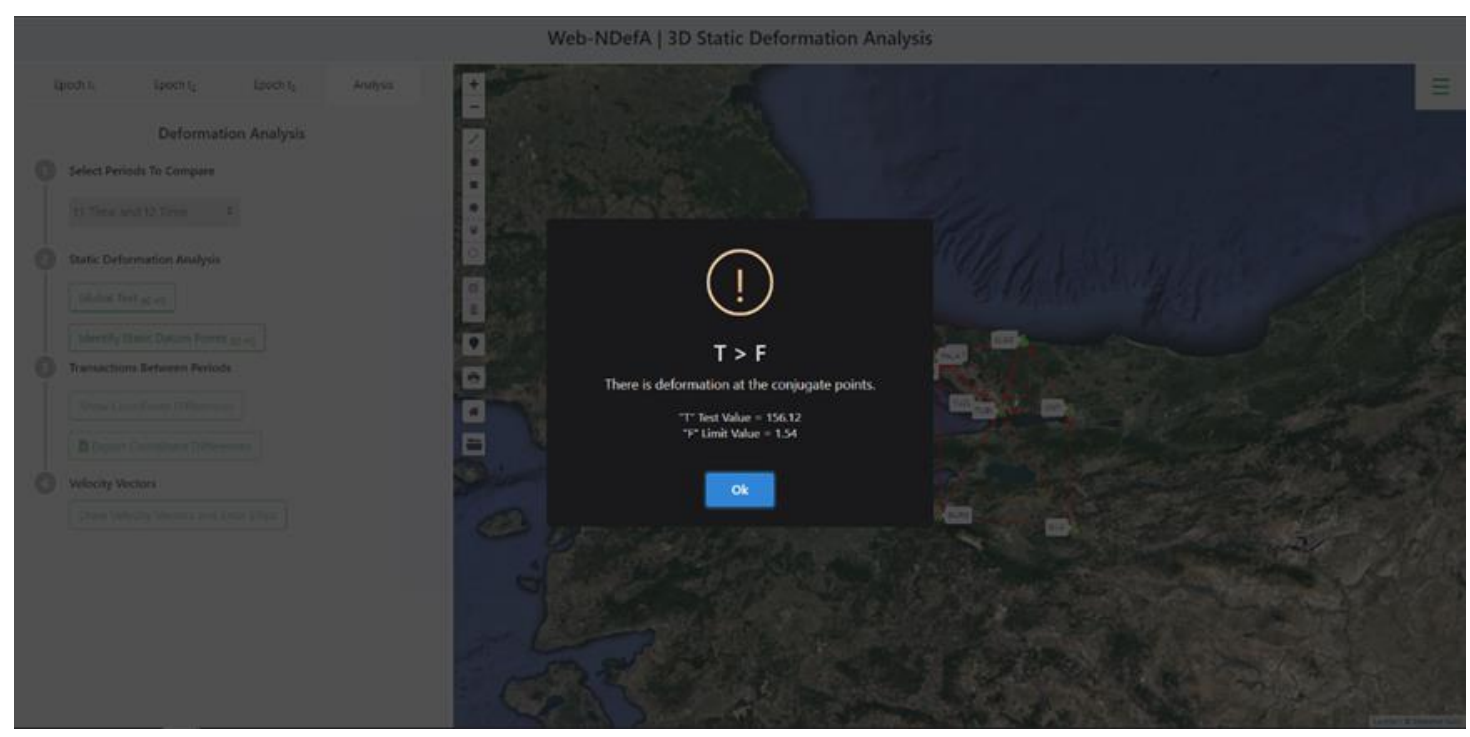

Şekil 16: Global test

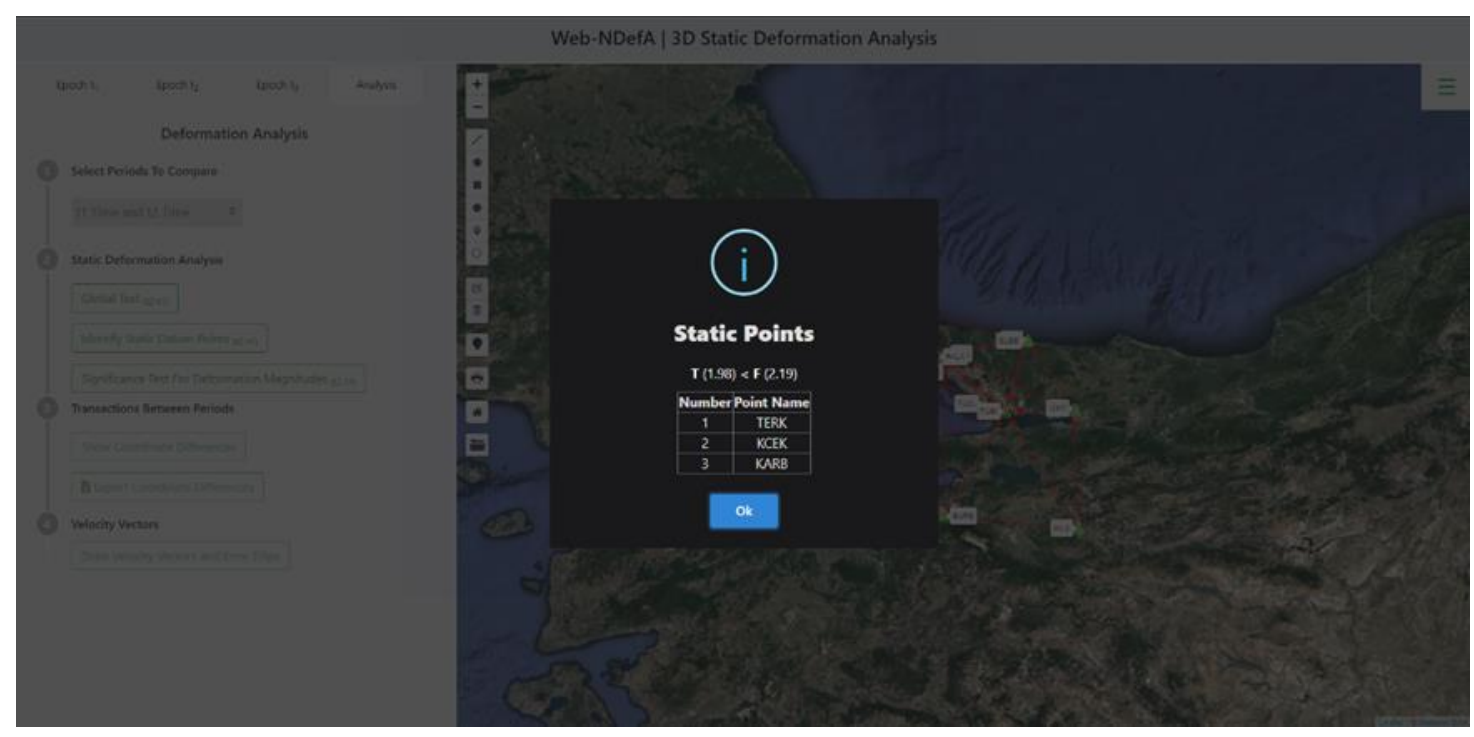

Şekil 17: Hareketsiz datum noktaları

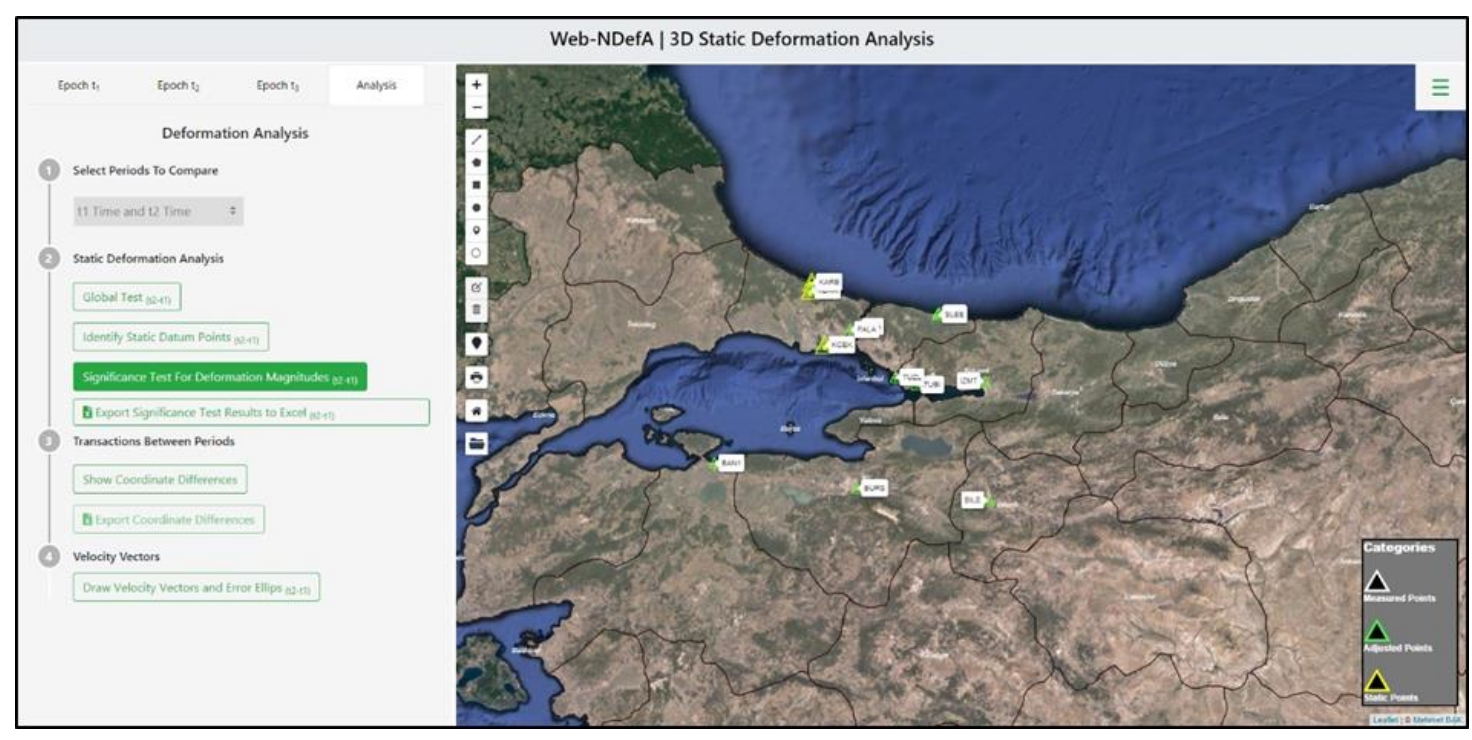

Şekil 18: Hareketsiz datum noktalarının ve geri kalan noktaların harita üzerindeki konumları 


\begin{tabular}{|c|c|c|}
\hline \multicolumn{3}{|c|}{ Significance Test Results } \\
\hline Point Name ${ }_{(t 2-t 1)}$ & Test Value $_{(t 2-t 1)}$ & F Value $_{(t 2-11)}$ \\
\hline BAN1 & 301.31 & 2.69 Point motion is significant. \\
\hline BILE & 336.64 & 2.69 Point motion is significant. \\
\hline BURS & 413.58 & 2.69 Point motion is significant. \\
\hline ISTA & 4.24 & 2.69 Point motion is significant. \\
\hline TUBI & 42.59 & 2.69 Point motion is significant. \\
\hline PALA & 1.91 & 2.69 Insignificant. \\
\hline SILE & 0.47 & 2.69 Insignificant. \\
\hline TUZL & 14.61 & 2.69 Point motion is significant. \\
\hline IZMT & 26.56 & 2.69 Point motion is significant. \\
\hline SLEE & 6.16 & 2.69 Point motion is significant. \\
\hline
\end{tabular}

Şekil 19: Deformasyon noktaları için .xls formatında anlamlılık test sonuçları

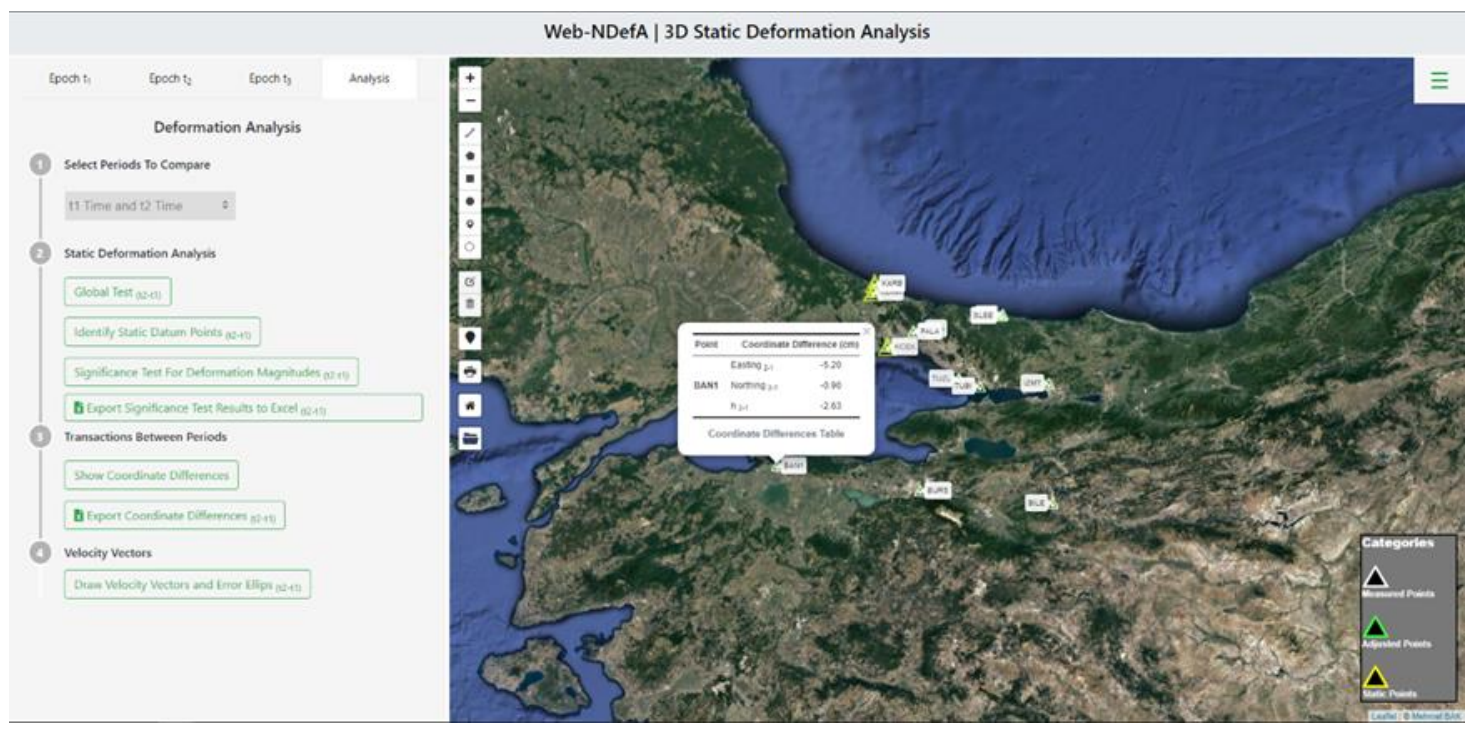

Şekil 20: Koordinat farklarının haritada nokta üzerinde gösterilmesi

\begin{tabular}{|c|c|c|c|c|c|c|}
\hline \multicolumn{7}{|c|}{ Coordinate Differences Table (t2-t1) } \\
\hline \multirow{3}{*}{$\begin{array}{l}\text { Point } \\
\text { Name }\end{array}$} & \multicolumn{3}{|c|}{ UTM/TM Coordinate Difference } & \multicolumn{3}{|c|}{ Topocentric Coordinate Difference } \\
\hline & \multicolumn{3}{|c|}{$(t 2-t 1)$} & \multicolumn{3}{|c|}{$(t 2-t 1)$} \\
\hline & Easting $(\mathrm{cm})$ & Northing (cm) & $\mathrm{h} \mathbf{c m}$ & East $(\mathrm{cm})$ & North $(\mathrm{cm})$ & Up (cm) \\
\hline BAN1 & -5.2000 & -0.9000 & -2.6300 & -5.2590 & -1.0210 & -2.6252 \\
\hline BILE & -6.2000 & -0.5000 & -3.8700 & -6.1717 & -0.4569 & -3.8668 \\
\hline BURS & -5.7000 & -0.8000 & -6.7300 & -5.7004 & -0.8375 & -6.7282 \\
\hline ISTA & 0.0000 & 0.0000 & 1.2300 & 0.0198 & -0.0253 & 1.2289 \\
\hline TUBI & -1.2000 & 0.0000 & -2.5100 & -1.2630 & -0.0816 & -2.5126 \\
\hline PALA & 0.0000 & 0.1000 & 1.2700 & 0.0059 & 0.1097 & 1.2660 \\
\hline SILE & 0.2000 & 0.0000 & -0.0300 & 0.1889 & -0.0116 & -0.0251 \\
\hline TUZL & -1.0000 & 0.2000 & -2.5400 & -0.9665 & 0.1619 & -2.5372 \\
\hline IZMT & -1.2000 & 0.0000 & -2.6400 & -1.1640 & -0.0048 & -2.6371 \\
\hline SLEE & 0.7000 & 0.7000 & 0.0200 & 0.6628 & 0.6770 & 0.0206 \\
\hline
\end{tabular}

Şekil 21: Koordinat farklarının .xls formatında tablosu 


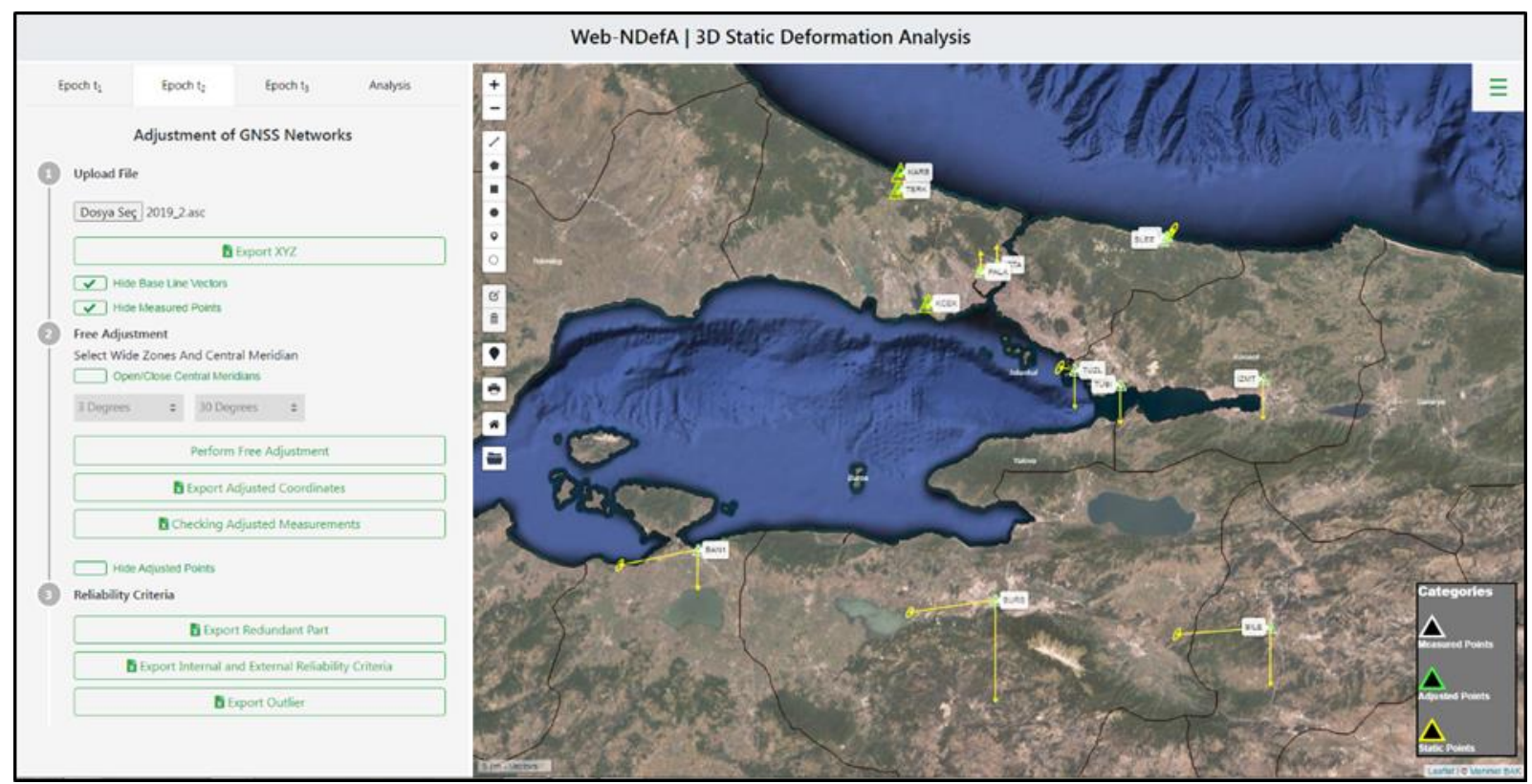

Şekil 22: Yer değiştirme vektörleri ve hata elipsleri

\section{Sonuçlar}

$\mathrm{Bu}$ çalışmada elde edilen sonuçlar incelendiğinde; deformasyon ağlarının değerlendirilmesine yönelik hazırlanan bu web uygulaması ile LGO yazılımından GPS ölçülerinin değerlendirilmesine ait elde edilen ASCII dosyasının platforma yüklenerek ölçülerin serbest ağ yöntemine göre dengelenmesi, güven ölçütlerinin elde edilmesi, statik deformasyon modeline göre ve S-Transformasyon yöntemiyle karşılaştırılan ağların analizlerinin yapılması, koordinat farklarının hesaplanması ve hız vektörlerinin çizdirilmesi görsel bir şekilde incelenmiş olur. Böylece uygulama, sürekli değişim halindeki yer kabuğu hareketlerinin belirlenmesini veya başka bir ihtiyaca yönelik deformasyon analizi çalışmalarını kolaylaştıracaktır. Platform açık kaynak kodlu yazılımlar ile geliştirildiğinden başka bir amaca veya hedefe yönelik çalışmalar için de gelişme esnekliğine sahiptir. Bu bağlamda platform şu anda sadece LGO yazılımından elde edilen baz çözümleri ile analiz yapıyor olsa da başka değerlendirme yazılımlarından gelen çözümlere ait dosyaların kullanılabilirliğinin sağlanmasıyla çok daha faydalı hale gelmiş olacaktır. Bu yapılan çalışma ayrıca web tabanlı açık kaynak kodlu yazılımlar yardımıyla deformasyon analizlerinin yapılabilirliği, kullanımı ve uygulanabilirliği açısından önemlidir.

\section{Çıkar Çatışması Beyanı}

Yazarlar, bu çalışmada bilinen ilgili herhangi bir finansal veya finansal olmayan çıkar çatışması olmadığını beyan eder.

\section{Yazar Katkısı}

Mehmet Bak: Fikir, Literatür taraması, Analiz ve yorumlama, Yazım. Rahmi Nurhan Çelik: Tasarım, Denetleme, Makale değerlendirme. 


\section{Kaynaklar}

Akyılmaz, O., Acar, M., \& Özlüdemir, M. T. (2007). Koordinat Dönüşümünde En Küçük Kareler ve Toplam En Küçük Kareler Yöntemi. Jeodezi, Jeoinformasyon ve Arazi Yönetim Dergisi, 16

Baarda, W. (1973). S-transformation and criterion matrices, Netherlands Geodetic Commission Publications on Geodesy. New Series, $5(1)$.

Bak, M. (2014). Jeodezik Çalışmalarla İzmit Körfezi Ve Yakın Çevresi Kabuk Deformasyonlarının Belirlenmesi (Yüksek Lisans Tezi). İstanbul Teknik Üniversitesi, Fen Bilimleri Enstitüsü, İstanbul, Türkiye

Başkaya, B. (1995). S - Transformasyonu ve yatay kontrol ağlarında deformasyon analizi (Doktora Tezi). İstanbul Teknik Üniversitesi, Fen Bilimleri Enstitüsü. İstanbul, Türkiye.

Bayrak, T., \& Yalçınkaya, M. (2002). Statik ve Kinematik Modelde Deformasyon Analizi. Selçuk Üniversitesi Jeodezi ve Fotogrametri Mühendisliği Öğretiminde 30. Yıl Sempozyumu. Konya.

Caspary, W., \& Rueger, J. M. (1987). Concepts of network and deformation analysis. Edited by J.M. Rueger. School of Surveying, University of New South Wales Kensington.

Demirel, H. (1987). S Transformasyonu ve Deformasyon Analizi. 1. Türkiye Harita Bilimsel ve Teknik Kurultayl, 593-608.

Demirel, H. (2009). Dengeleme Hesabı. Yıldız Teknik Üniversitesi Basım - Yayın Merkezi.

Doğanalp, S., \& Turgut, B. (2009). Statik ve Kinematik Modelde Deformasyon Analizi. Selçuk Üniversitesi Mühendislik, Bilim ve Teknoloji Dergisi, 24(2), 31-44.

Erdoğan, B., \& Mandalinci, G. (2019). Robust kestirim yöntemlerinin deformasyon analizinde uygulanmasında farklı yaklaşımların güvenilirliğinin araştırılması. Jeodezi ve Jeoinformasyon Dergisi, 6(1), 10-25.

Erol S. (2008). GPS ve Nivelman Ölçüleriyle Deformasyonların Belirlenmesi (Doktora Tezi). Yıldız Teknik Üniversitesi, Fen Bilimleri Enstitüsü, İstanbul, Türkiye.

Gründig, L., Neureither, M., \& Bahndorf, J. (1985). Detection and localization of geometrical movements. Journal of Surveying Engineering, 111(2), 118-132.

Özdemir, E. G. (2022) Bağıl ve mutlak (PPP) konum çözüm yaklaşımı sunan Web-Tabanlı çevrimiçi veri değerlendirme servislerinin farklı gözlem periyotlarındaki performanslarının araştırılması. Geomatik, 7(1), 41-51.

Pelzer, H. (1971). Zur Analyse geodatischer Deformations-messungen, Deutsche Geodätische Kommission, C-164, München, Germany. Pırtı, A., \& Yazıcı, D. (2022). İnternet tabanlı GNSS yazılımlarının doğruluk açısından değerlendirilmesi. Geomatik, 7(2), 88-105.

Şimşek, M., Özarpacı, S., \& Doğan, U. (2019). Yer Kabuğu Hareketlerinin Belirlenmesinde Web Tabanlı Çevrimiçi GNSS Servislerinin Performans Analizi. Geomatik, 4(2), 147-159.

van Hees, G. S. (1982). Variance-covariance transformations of geodetic networks. Manuscripta Geodaetica, 7(1), 1-20.

van Mierlo, J. (1981). A testing procedure for analysing geodetic measurements. In Proceedings of the 2nd International Symposium on Deformation Measurements by Geodetic Methods, Bonn (Ed. L. Hallermann). Konrad Wittwer, Stuttgart (pp. 321-352).

Welsch, W. M. (1993). A general 7-parameter transformation for the combination, comparison and accuracy control of terrestrial and satellite network observations. Manuscripta geodaetica, 18(5), 295-295.

Yalçınkaya, M., Teke, K., \& Bayrak, T. (2003). Jeodezik GPS Ağlarında Duyarlık ve Güven Analizi. 1. Ulusal Mühendislik Ölçmeleri Sempozyumu. İstanbul.

Yalçınkaya, M. (2019). Deformasyon Ölçüleri ve Analizi Ders Notu.

URL-1: Web-NDefA, https://github.com/mhmtbk/Web-NDefA, (Erişim Tarihi: 15.10.2020).

URL-2: International GNSS Service: https://kb.igs.org/hc/en-us/articles/115003935351, (Erişim Tarihi: 15.03.2020).

URL-3: Scripps Orbit and Permanent Array Center, https://sopac.ucsd.edu/, (Erişim Tarihi 15.03.2020).

URL-4: International Terrestrial Reference Frame, https://itrf.ign.fr/, (Erişim Tarihi: 15.03.2020).

URL-5: Türkiye Ulusal Sabit GNSS Ağ1, https://www.tusaga-aktif.gov.tr/, (Erişim Tarihi 15.03.2020).

URL-6: İstanbul Su ve Kanalizasyon İdaresi Uydularlardan Konum Belirleme Sistemi, https://ukbs.iski.gov.tr/, (Erişim Tarihi 15.03.2020). 